\title{
Social stratification in downgrading during secondary school after ambitious track choices
}

Jascha Dräger ${ }^{1,2 *}$

Jascha.draeger@gesis.org

Leo Röhlke ${ }^{1}$

Leo.roehlke@web.de

\author{
Alina Dippel ${ }^{1}$ \\ Alina.dippel@gesis.org \\ ${ }^{1}$ GESIS - Leibniz Institute for the Social Sciences \\ ${ }^{2}$ University of Leipzig \\ * Corresponding Author
}

\section{Acknowledgements}

This paper uses data from the National Educational Panel Study (NEPS): Starting Cohort Grade 5, doi:10.5157/NEPS:SC3:10.0.0. From 2008 to 2013, NEPS data was collected as part of the Framework Program for the Promotion of Empirical Educational Research funded by the German Federal Ministry of Education and Research (BMBF). As of 2014, NEPS is carried out by the Leibniz Institute for Educational Trajectories (LIfBi) at the University of Bamberg in cooperation with a nationwide network.

We would like to thank Nora Müller, Klaus Pforr, and Tobias Roth for feedback on earlier drafts.

\section{Funding}

This work was supported by the "German Research Foundation" (DFG) under Grant No. 403547843. 


\title{
Social stratification in downgrading during secondary school after ambitious track choices
}

\begin{abstract}
It is well established in the literature on social stratification in educational attainment that children with high socio-economic status choose more academically demanding educational tracks than their peers, particularly if their prior school performance was poor. Much less is known about whether they stay on demanding secondary school tracks after such ambitious track choices or whether they downgrade to lower tracks. This study makes two contributions to the literature on compensatory advantage (CA): First, we evaluate whether high parental education compensates for a low academic preparedness and thereby reduces the risk of downgrading from the academic track of secondary school in Germany. Second, we try to identify the underlying mechanisms: The CA could either be attributed to children catching up academically or to different reactions to poor performance on the academic track. We follow the educational trajectories of 2,371 children who transferred to the academic track in 2010 using survival analysis. In line with CA, we find that among the children with low academic preparedness, those with high parental education are less likely to downgrade to a lower track. The differences in downgrading by academic preparedness and parental education can be partially attributed to the performance on the academic track. However, we do not find evidence for the proposed compensatory mechanisms. Neither the association between academic preparedness and performance on the academic track nor the association between performance on the academic track and the risk of downgrading is weaker for children with higher parental education. Instead, CA seems to result from the average advantages of having highly educated parents being more relevant for children at the edge of downgrading.
\end{abstract}

Keywords: Compensatory Advantage, Educational Attainment, Survival Analysis, Tracking 


\section{Introduction}

It is well established in the literature on stratification in educational attainment, that children of parents with high socio-economic status (SES) are more likely than children of parents with low SES to choose more academically demanding educational pathways. These differences can be partially attributed to socially stratified differences in school performance (i.e., primary effects). However, large SES differences in educational decisions remain even when adjusting for school performance (i.e., secondary effects; Boudon, 1974; Erikson et al., 2005; Jackson, 2013).

While enrollment decisions in secondary school tracks are well-researched, much less is known about whether children remain on the more demanding tracks, especially when the prior enrollment decision was ambitious. We consider enrollment decisions as being (academically) ambitious if the prior academic performance of the child is below or at the threshold of the performance level that is expected to enter this educational track. We will refer to this as low academic preparedness in the following. Previous studies on transitions between subsequent educational institutions have largely neglected the possibility for failure within institutional tracks. Ambitious track choices will only result in higher educational attainment if they are not offset by performance-based selection after the transition. Several open questions remain: To what extent do children with low academic preparedness leave the most demanding secondary school track again and downgrade to a lower track? Can high parental SES compensate for low academic preparedness and prevent downgrading? If yes, how do high-SES families achieve this?

The compensatory advantage (CA) theory provides a framework to answer these questions. CA proposes that life course trajectories (here educational trajectories) of children from privileged backgrounds are less affected by prior negative events or outcomes (here poor school performance) because these families can better atone them (F. Bernardi, 2014). CA complements the notion of path dependency (and cumulative advantage) by emphasizing the heterogeneity of the latter: High-SES is particularly effective in breaking the path dependency of negative events, preventing a certain trajectory from becoming 'locked in' as a result of an early negative event (F. Bernardi, 2014, p. 74f.). The idea of CA is rooted in the theory of risk aversion (Breen \& Goldthorpe, 1997), which argues that the motivation to avoid status demotion leads high-SES families to behave differently in response to events threatening their children's educational attainment: they are more likely to successfully compensate for such events (F. Bernardi, 2014). Previous research on secondary school track choice has found much 
evidence for CA: Particularly among low- or average-performing children, high-SES children are much more likely to choose more demanding tracks (F. Bernardi, 2012; F. Bernardi \& Cebolla-Boado, 2014a, 2014b; F. Bernardi \& Triventi, 2020; Gil-Hernández, 2021; Holm et al., 2019; Neugebauer, 2010). Our paper makes two contributions to this growing body of literature.

On one hand, we evaluate whether parental SES compensates for a low academic preparedness by reducing the risk that children will downgrade from the most demanding to a lower track. It is all but clear that we observe CA here because by evaluating only children on the demanding track, we consider a very particular sample: The low-SES children who attend the most demanding track are a selective subsample (with respect to academic preparedness and aspirations) of all low-SES children. In contrast, the high-SES children are much less selected with respect to their academic preparedness. Moreover, previous studies on school track changes in Germany and the Netherlands found only weak evidence for social stratification (Hillmert \& Jacob, 2010; Jacob \& Tieben, 2009; Kloosterman \& de Graaf, 2010). Track changes in stratified school systems have generally not received much attention and have never been analyzed as a potential case of CA.

On the other hand, our study investigates the underlying mechanisms of CA. First, we evaluate whether the hypothesized CA in the risk of downgrading can be attributed to differences in performance on the demanding track. Second, we evaluate whether high-SES breaks the link between academic preparedness and performance on the demanding track ('catch-up mechanism'). Third, we evaluate whether high-SES breaks the link between performance on the demanding track and track changes ('carry-on mechanism').

We test these mechanisms exemplarily for the academic secondary school track ('Gymnasium') in Germany. We prospectively follow the educational trajectories of 2,371 children who transferred to the academic track in 2010 until the end of $9^{\text {th }}$ grade using the data of the German National Educational Panel Study. Germany is an interesting case for this study because tracking already takes place after the fourth grade, families have the free choice about tracks in most federal states, and track attendance is strongly socially stratified (Neugebauer, 2010; Neugebauer et al., 2013). Moreover, the tracking system is rather inflexible, and the attended track is highly predictive of final educational attainment (Hillmert \& Jacob, 2010; Neugebauer \& Schindler, 2012; Schneider, 2008) and labor market outcomes (Dustmann et al., 2017; Traini et al., 2021). Therefore, families are both able and motivated to make ambitious tracking decisions. Additionally, there is more time for track changes than in most other countries. 
In the following, we will shortly review the existing research on track changes and how they are related to academic preparedness and parental SES. We then present two complementary mechanisms which may explain how high parental SES may increase the chances to remain on the academic track despite low academic preparedness. After discussing the institutional context of Germany and its implications for our study, we present the data and research design. In the results section, we will briefly evaluate the selectivity of children attending the academic track, and then test whether and why a high parental education compensates for a low academic preparedness in this selective sample.

\section{Literature review}

Research on the downgrading risk of children with a low academic preparedness and research on social stratification in downgrading has been largely separated so far. On the one hand, studies in educational science found that children who attend the academic track against the recommendation of their teachers are more likely to leave this track again (Albrecht et al., 2018; Baeriswyl et al., 2010; M. Bernardi et al., 2014; Klapproth et al., 2013; Scharenberg et al., 2009).

On the other hand, several studies found that the risk of downgrading from the academic track is socially stratified, but less strongly than for enrollment decisions, e.g., to secondary school tracks. For Germany, both Schneider (2008) and Winkler (2017) found that about $70 \%$ of the high-SES children succeeded at the highest track compared to about $60 \%$ of low-SES children. Ditton (2013) also showed that parental education reduced the risk of downgrading, net of academic performance. For the Netherlands, both Tieben \& Wolbers (2010) and Kloosterman $\&$ de Graaf (2010) reported that, among the children who initially transferred to the academic track, high-SES children were less likely to drop out and more likely to graduate. Jacob \& Tieben (2009) found no effect of parental education on the likelihood of secondary school downgrading in both Germany and the Netherlands but reported some stratification in upward track changes.

Only a handful of studies investigated if the effect of low academic preparedness on dropout from a secondary school track differs by parental SES. Bernardi \& Triventi (2020) analyzed whether parental SES compensates for the negative effect of poor middle school grades on the chance of completing upper secondary education in Italy. They found strong evidence for such compensation, which explained a substantial share of the overall social inequality in completion rates. Lohmann \& Groh-Samberg (2010) found that in Germany, among children without a 
recommendation for the highest secondary school track, those with highly educated parents were more likely to still attend the highest track at the age of 17 . However, the interaction between the recommendation and parental education was small and not statistically significant. Holm et al. (2019) showed that academic preparedness and the chance of completing the upper secondary track in Denmark were more strongly associated when parental SES was low. Two other studies found compensatory effects on secondary school dropouts with regard to other negative events, like less generous maternal leave entitlements (Carneiro et al., 2015), or motherly full-time employment in early childhood (Ermisch \& Francesconi, 2013). None of these studies further explored why children had dropped out prematurely or explicitly analyzed downgrading to a lower track as opposed to leaving secondary education entirely.

By now, not much is known about the processes leading to secondary school track changes. Most studies assume that poor academic performance on the current track is the main cause of downgrading (Hillmert \& Jacob, 2010, p. 66; Jacob \& Tieben, 2009, p. 751). Empirical results generally confirm that academic performance is an important determinant of track changes (Albrecht et al., 2018; Bittmann, 2021; Ditton, 2013; Dittrich, 2014; Tiedemann \& BillmannMahecha, 2010). The literature on high school dropout suggests that a poor academic performance can further trigger a cascade of negative ramifications mostly of psychological nature ('affective detachment from school') which may ultimately result in dropouts (De Witte \& Rogge, 2013, p. 213f.).

Two recent studies investigated compensation mechanisms regarding low academic preparedness not within secondary, but higher education. For Italy, Contini et al. (2018) found large SES differences in the success (dropout and timely completion) in higher education among the students who performed poorly in primary and secondary school and attended the vocational school track. In contrast, they found social stratification to be much lower among the students who had achieved good grades in secondary school. A French study demonstrated that the effect of a given poor performance in higher education on the risk of dropout depends is weaker for high-SES students (Herbaut, 2020).

\section{Theory}

\subsection{Theoretical framework}

Most existing studies have evaluated CA for enrollment decisions. In contrast, we want to evaluate whether children change tracks again after enrollment. This idea is visualized in Figure 1. The CA in the risk of downgrading is represented by the purple arrow. Obviously, only 
children who attend the academic track are at risk of downgrading from it. Thus, the first selection by academic preparedness and parental SES for enrollment decisions already took place.

[Figure 1 about here]

Downgrading to a lower track may either be 'voluntary' when continuing the current track would have been possible, or 'involuntary', when institutional restrictions enforce leaving the current track. Involuntary downgrading is rather exceptional in Germany (see section 4). The phenomenon of voluntary downgrading requires sociological explanation: Why should families reverse their initial decision, deciding that a lower track is the better option although they had chosen the academic track in the first place?

Many aspects that families may have considered for their initial decision, like the labor market prospects or the likelihood of social downward mobility with different school leaving certificates, will not change while children attend the academic track. What may change is how children evaluate their chances of graduating successfully. Particularly when tracking takes place early, families possess insufficient information on the true (individual) difficulty of a particular track before enrolling. Poor performance on the academic track signals that the probability to succeed on the academic track may be lower than expected (Holm et al., 2019) and that children may have to invest more time into learning or that private tutoring may be required. With the lower-than-expected probability to succeed and higher costs, downgrading to another track may become the more attractive alternative than staying on the academic track.

Children who made an ambitious track choice (those with low academic preparedness), will be most likely to perform poorly, and therefore, will be most likely to downgrade. In other words: the association between academic preparedness and the risk of downgrading will largely be mediated by performance on the academic track.

Moreover, higher-SES children and their parents should be more motivated to stay on the academic track. Avoiding social downward mobility with any but the highest school leaving certificates may be almost impossible for high-SES children. In contrast, for low-SES children, getting the highest school leaving certificate is not necessary to avoid downward mobility (Breen \& Goldthorpe, 1997).

The SES differences in the motivation to stay on the academic track should be particularly important for children with low academic preparedness because children with a low academic preparedness have a higher risk of downgrading in general. In contrast, children who are 
academically well prepared will perform better on the academic track, and therefore, will rarely downgrade - independent of their SES. Thus, a high SES compensates for a low academic preparedness.

We suggest two complementary moderating mechanisms that may yield the overall CA in downgrading risk: First, high-SES children may be better able to catch up with the minimum performance level expected on the highest track than low-SES children (catch-up mechanism: blue arrow in Figure 2). Second, even when secondary school GPA is indeed poor, high-SES children may nevertheless be more likely to carry on their school career at the highest track compared to low-SES children (carry-on mechanism: red arrow). This type of compensation would hence not be related to increased GPA but to a different reaction to the same poor GPA between lower and higher SES families. In the following, we will describe the two mechanisms in more detail, referring to common arguments from the literature on CA: resource mobilization (F. Bernardi, 2014; F. Bernardi \& Grätz, 2015; Schneider \& Linberg, 2021) and responsiveness to ability information (F. Bernardi \& Cebolla-Boado, 2014b; F. Bernardi \& Triventi, 2020; Holm et al., 2019).

[Figure 2 about here]

\subsection{The catch-up mechanism}

High-SES families possess more financial, cultural, and social resources that may improve a child's secondary school GPA, particularly when primary school performance is poor. They may not only be better endowed but also more motivated to invest these resources (Stienstra et al., 2020) and their investments may be more effective (McNeal Jr, 1999). This mobilization of resources may help high-SES children with low academic preparedness to catch up over time (blue arrow in Figure 2), decreasing the performance gap between them and their classmates (F. Bernardi, 2014; F. Bernardi \& Grätz, 2015; Schneider \& Linberg, 2021). We assume that these investments should be most beneficial for children with lower academic preparedness (Grätz \& Bernardi, 2017; Grätz \& Wiborg, 2020). According to the theory of relative risk aversion, parents are more motivated to invest resources into their children's education when status reproduction is threatened. There is some evidence for the idea that high-SES children are more likely to catch up regarding their cognitive skills than low-SES children (Schneider \& Linberg, 2021, p. 6).

Better economic resources may benefit underperforming high-SES children through fee-paying tutorials (Huang, 2020; Park et al., 2011) or tuition fees for private schools with better learning 
conditions (Hoffmann et al., 2019). Because of their better knowledge of the educational system, high-SES parents may generally be better able to identify certain secondary schools which provide more favorable conditions for struggling students (F. Bernardi \& Cebolla-Boado, 2014b, p. 210; F. Bernardi \& Grätz, 2015, p. 237). Highly educated parents are better endowed for helping with homework, and studying for exams (F. Bernardi \& Grätz, 2015). High-SES parents are also more involved in interactions with school and teachers and are better endowed to achieve their goals in these matters, possibly influencing the teachers' grading (Dumont et al., 2019; Park et al., 2011). Alternatively, pressure from family and peers may make high-SES children themselves more motivated to invest more time in studying (Grätz \& Bernardi, 2017, p. 72).

Yet, high-SES parents already start investing in their children's competences during primary school (Bach \& Fischer, 2020; Dumont et al., 2019). Why should high-SES children with low academic preparedness have better chances to increase secondary school performance than lowSES children, although the performance-enhancing effect of SES did not prevent them from underperforming in primary school? First, the higher investments by high-SES families in primary school may partly pay off later, improving children's performance in secondary school in a cumulative way. Second, there may be larger SES differences between parents' support capacities in secondary school than in primary school. Most parents, even those with low education, will be able to help their children with the learning content in primary school. However, in secondary school (especially when considering the most demanding track), only better-educated parents may be able to help their children with the more difficult curricula, for instance with a third language.

\subsection{The carry-on mechanism}

The same GPA in secondary school may affect dropout decisions differently, depending on parental SES (red arrow in Figure 2). We argue that high-SES children with the same bad grades will be less likely to downgrade than low-SES children and more likely to just "carry on". In this logic, a lower responsiveness to poor performance will result in CA (F. Bernardi \& Cebolla-Boado, 2014b; F. Bernardi \& Triventi, 2020; Holm et al., 2019). A recent study by Holm et al. (2019) supports this argument. They showed that 'information shocks' after enrolment (resulting from poor GPA) were more consequential for the track completion of children from lower-SES families. Two related arguments support this proposition:

First, low-SES families may adjust their subjective probability of success more strongly to the child's current GPA than high-SES families (Holm et al., 2019). Especially at the start of upper 
secondary education, parents face incomplete information about their child's probability of succeeding in the academic track. Low-SES families are less familiar with the educational system and have few other sources of information about their child's probability of success besides the child's grades. In addition, low-SES parents tend to attribute bad grades to a lack of ability rather than to a lack of effort (Iatridis \& Fousiani, 2009). Finally, they may be less confident than high-SES parents regarding their future capacity to positively influence their child's school performance.

Second, the subjective probability of success matters less for continuation decisions in highSES families. Under the assumptions of the relative risk aversion theory, the subjective probability of success is no relevant parameter for high-SES families (Lucas, 2009). If there is any chance that children may graduate from the highest track, high-SES families may prefer this small chance over downgrading to a lower track which almost certainly will result in downward mobility. In contrast, a low probability of success may outweigh potential benefits from staying on the academic track for low-SES children.

\subsection{Hypotheses}

Based on these arguments, we derive the following hypotheses:

Hypothesis 1a: Children with low academic preparedness are more likely to downgrade from the academic track than children with high academic preparedness (Academic preparedness $\rightarrow$ Risk of downgrading in Figure 1).

Hypothesis $1 \mathrm{~b}$ : The negative effect of low academic preparedness on the risk of downgrading will be weaker for high-SES children than for low-SES children (Compensatory Advantage; purple arrow in Figure 1).

Hypothesis 2: The compensatory advantage in downgrading risk for high-SES children with low academic preparedness can be partially attributed to performance on the academic track (Mediation of CA; Academic preparedness $\rightarrow$ Performance on the academic track $\rightarrow$ Risk of downgrading in Figure 2).

Hypothesis 3a: Children with low academic preparedness will perform worse on the academic track than children with high academic preparedness (Academic preparedness $\rightarrow$ Performance on the academic track in Figure 2). 
Hypothesis 3b: The negative effect of low academic preparedness on performance on the academic track will be weaker for high-SES children than for low-SES children (Catch-up mechanism; blue arrow in Figure 2).

Hypothesis 4a: Children with poor performance on the academic track are more likely to downgrade from the academic track than children with good performance (Performance on the academic track $\rightarrow$ Risk of downgrading in Figure 2).

Hypothesis $4 b$ : The negative effect of poor performance on the academic track on the risk of downgrading will be weaker for high-SES children than for low-SES children (Carry-on mechanism; red arrow in Figure 2).

\section{Institutional context}

Children in Germany are tracked exceptionally early, in most federal states after only four years of schooling. They are sent to three different tracks. The two lower tracks, Hauptschule and Realschule end after nine or ten years of schooling, respectively; the academic track (Gymnasium) after twelve or thirteen. Additionally, some schools do not track or offer multiple tracks (e.g., comprehensive schools). Only graduation from Gymnasium (Abitur) grants direct and unrestricted access to higher education. Differences between schools of the same track are comparatively small in terms of equipment and teacher quality.

Parents usually receive a track recommendation for their child by their child's primary school teachers. The teachers' recommendation is based on performance in primary school and their subjective assessment of the child's ability to fulfil the requirements of the different tracks. Yet, in 12 of the 16 federal states teachers' recommendations are not binding and parents can decide freely about which track their child should attend. In four federal states (Bavaria, Brandenburg, Saxony, Thuringia), deviating upwards from the recommendations is more difficult but children can still attend Gymnasium if their parents participate in a counselling interview, or the children pass an entrance exam or a probation period. ${ }^{1}$

It is possible to change to a lower (or higher) track later. If children or their parents feel like the current track is too challenging, they can decide to change schools and tracks without any prerequisites. In some states, there is an orientation stage (usually the first year or the first two years) at the end of which children must prove that they are suitable for continuing their education at a Gymnasium. In many federal states, schools can also enforce a downgrade to a

\footnotetext{
${ }^{1}$ All regulations apply to the year 2010, when the children in our data set transferred to secondary schools.
} 
lower track, but only in the rather exceptional case that the child would have to repeat two subsequent years or the same year twice. Independent of the chosen track, children are required to stay in the general schooling system for at least nine years.

Official data about track changes are only available as a combination of upward and downward changes (Autorengruppe Bildungsberichterstattung, 2020, pp. 111-116). In general, track mobility is low and downgrading occurs seldomly. The share of students who changed tracks between $5^{\text {th }}$ and $7^{\text {th }}$ grade is below 3\%. Nearly half of the changes in the year 2016/17 were transitions from Gymnasium to a lower track. Moreover, analyzing data of the NEPS-SC3 (the same data that we will analyze), the authors of the report foundthat about $91 \%$ of the children who attended schools that only host Gymnasium classes in the $5^{\text {th }}$ grade still attend Gymnasium in the $11^{\text {th }}$ grade. ${ }^{2}$

The institutional context described in this section makes Germany an interesting case for testing our theoretical arguments: Because most German parents are aware that secondary track placement is a strong predictor of later educational attainment, the incentive for making ambitious transitions is high. However, the institutional barriers leave only limited room for parental choice (Gil-Hernández, 2021). The relatively strict ability-tracking and the low mobility between tracks enable us to conduct a stringent test of CA. Because downgrading is mostly voluntary, we can also test both the catch-up and the carry-on mechanism.

\section{Data \& methods}

\subsection{Data}

For our empirical analysis, we use the data of the German National Educational Panel Study (Blossfeld \& von Maurice, 2011), starting cohort $5^{\text {th }}$ grade $($ NEPS-SC3; doi:10.5157/NEPS:SC3:10.0.0). NEPS is the only study that allows us to prospectively follow a large, representative sample throughout their entire secondary school careers in Germany. The target population of NEPS-SC3 was all children who attended the $5^{\text {th }}$ grade at regular schools in fall 2010. In the first wave, 5,778 children participated. Participating children were questioned annually since. An additional interview round was conducted in spring 2015 when most children were in the second semester of the $9^{\text {th }}$ grade. In addition, the children's parents were invited for interviews in waves 1-4 and 6. For our analysis, we consider all 4,803 children who attended the $5^{\text {th }}$ grade of schools in the tracked secondary school system in fall 2010

\footnotetext{
${ }^{2}$ However, this is likely an overestimation because schools which offer multiple tracks are considered separately, students who left the survey early were excluded from this analysis, and the original track variable in NEPS does not capture all changes that happened (see supplementary materials A).
} 
(Hauptschule, Realschule, Gymnasiums, schools with multiple tracks). We exclude children who still attended a primary school, were in the orientation stage or attended special need schools in fall 2010. ${ }^{3}$ For the analysis of whether children stay in Gymnasium, we consider the 2,371 children who were enrolled in Gymnasium in the $5^{\text {th }}$ grade. ${ }^{4}$

\subsection{Variables}

\section{Outcome: Current Track}

Our dependent variable is the current school track. We focus on children's track between the $5^{\text {th }}$ and $9^{\text {th }}$ grade because information on the children's current track was mainly obtained from the parents' interview. Since parents were surveyed the last time at the end of $9^{\text {th }}$ grade, there is a large proportion of missing information afterwards and a higher attrition rate from the panel. For the analysis, we distinguish between three states:

1) currently attending a Gymnasium (including children who attend a Gymnasium class in a comprehensive school or transferred from one Gymnasium to another),

2) having downgraded to another track (Hauptschule, Realschule, non-Gymnasium classes in comprehensive schools, or schools without tracking; hereafter downgraded), and

3) having left the survey before having downgraded (hereafter left survey).

We categorize all transitions to schools/classes that lead students to participate in the Abitur exams 'per default' as still attending a Gymnasium. Students who transfer to schools/classes that lead students to other certificates or require that students meet additional conditions to continue towards Abitur are categorized as downgrading. Thus, children who transfer to a comprehensive school without tracking are coded as a downgrade.

The track variable provided by the NEPS is based on parent interviews only. Unfortunately, the variable in its original form is unfit for our analysis. It captures almost no changes to lower tracks ( $\sim 30 \%$ missing values in total) and is unreliable for later waves. Hence, we augment the variable with other information available from the NEPS data including interviews with the

\footnotetext{
${ }^{3}$ Hereby, we implicitly exclude all students in the federal state of Berlin and most students from Brandenburg and Mecklenburg-Western Pomerania.

${ }^{4}$ In our study, we want to assess the association between academic preparedness, SES, and downgrading from Gymnasium among those students who attend the Gymnasium. Therefore, we do not adjust for the selection into Gymnasium. In the supplementary materials B, we discuss and evaluate the association between academic preparedness, SES and downgrading when taking the selection into Gymnasium into account. Thereby, we evaluate downgrading from Gymnasium under the counterfactual condition that all children have the same likelihood to attend the Gymnasium. We consider the former approach more interesting for the purpose of our descriptive analysis.
} 
children themselves as well as meta-data. We discuss our augmentation procedure in supplementary materials A.

\section{Parental SES}

We use parental education to measure SES because research found that parental education is a better predictor for children's educational attainment than other dimensions of parental SES like parental occupational class or income (Bukodi et al., 2021; Dräger \& Müller, 2020). Moreover, parental education captures more directly parental resources that may compensate for a low academic preparedness like parents' capacity to help children with schoolwork or knowledge of the educational system. We distinguish between households where at least one parent has a tertiary degree ('high parental education') and households where neither of the parents has a tertiary degree ('low parental education'). Parental education was measured in the first wave of NEPS.

In a robustness check, we use parental occupational class to measure SES. Here we use parents' highest EGP class and distinguish between parents in the service class (EGP I \& II), parents in the mixed class (EGP IIIa \& IV), and parents in the working class (EGP IIIb \& V to VII). We discuss the results of this robustness check in section 6.8 .

\section{Academic Preparedness}

We measure children's academic preparedness for the Gymnasium using children's average performance in two standardized competence tests (mathematics and reading) that took place at the beginning of the $5^{\text {th }}$ grade. The competence tests measure both curriculum-based competences and competences for daily life (Neumann et al., 2013). We standardize this average competence score to a mean of zero and a standard deviation of one for all children in the tracked system.

In a robustness check, we use two alternative measures of academic preparedness: children's average grade in mathematics and German in the last year of primary school and the track recommendation of teachers. However, the competence score is our preferred measure of children's academic preparedness because teachers' assigned grades and track recommendations might be affected by children's social origin, net of children's school performance. Moreover, grades are not standardized but teachers may grade students relative to the performance of their classmates.

\section{Performance in Gymnasium}


We measure children's performance in Gymnasium using their grades in German and mathematics received in the second term of $5^{\text {th }}$ to $9^{\text {th }}$ grade (plus grades received in the first term of $9^{\text {th }}$ grade). These grades range from 1 'very good' to 6 'insufficient'. Grades in other subjects were only reported sporadically.

\section{Control variables}

We control for children's migration background (native vs. first-generation migrant vs. secondgeneration migrant), household composition (both biological parents vs. single parents vs. biological parent with a new partner vs. other constellations), whether the family lives in East or West Germany, average age of parents, and age and gender of the child. All control variables were measured in the first wave of NEPS-SC3. Information was retrieved from parents and augmented with information from children if parents' information were not available.

\section{Multiple imputation}

We impute all missing values in independent variables using multiple imputation based on Categorization and Regression Trees (Burgette \& Reiter, 2010). We create 50 imputed datasets and apply Rubin's rules to obtain standard errors (Rubin, 1987).

\subsection{Analysis strategy}

We employ discrete-time competing-risk survival analysis (Prentice et al., 1978) to test hypotheses 1, 2 and 4. We use discrete-time survival analysis because most children change tracks between different academic years. The competing-risk survival analysis allows us to account for the censored information that we have for those children who still attend Gymnasium in the last wave and to incorporate the time-varying covariates. The quantity of interest in these models is the cause-specific hazards. The cause-specific hazard $\left(h_{j}\right)$ is the probability that children who still attend Gymnasium (i.e., are still 'at risk' of leaving it) leave the Gymnasium for one of the two causes ( $j$; downgrading vs. left survey) in the next academic year (t) (Lau et al., 2009):

$$
h_{j}=\operatorname{Pr}(T=t, J=j \mid T \geq t)
$$

where $T$ is the (potentially censored) academic year of leaving Gymnasium and $J$ the set of causes why children could leave the Gymnasium. We can evaluate whether the cause-specific hazards depend on characteristics of the children $(i)$ by applying multinomial logistic regression to all person-years where children are still at risk to leave the Gymnasium. Children's causespecific hazards depend on two aspects in this model: the average cause-specific hazard for a 
given academic year (i.e., the baseline hazard, $h_{0 j t}$ ) and a vector of children's characteristics $\left(\boldsymbol{X}_{i t}\right)$ :

$$
h_{i j} \mid t, \boldsymbol{X}_{i t}=\frac{\exp \left(h_{0 j t}+\beta_{\boldsymbol{j}} * \boldsymbol{X}_{\boldsymbol{i t}}\right)}{\sum_{j=1}^{J} \exp \left(h_{0 j t}+\beta_{\boldsymbol{J}} * \boldsymbol{X}_{i t}\right)}
$$

where $\beta_{j}$ a vector of the respective regression coefficients for a cause in contrast to all others. We estimate the baseline hazard fully flexible to avoid making potentially wrong parametric assumptions.

We test whether a high parental education can compensate for low academic preparedness by regressing the hazard of downgrading on children's academic preparedness, parental education, and their interaction (Hypotheses $1 a$ and $1 b$ ). In the next step, we add the children's GPA in Gymnasium to evaluate whether differences in hazard of downgrading can be attributed to differences in performance in Gymnasium (Hypothesis 2). To test the carry-on mechanism, we regress the hazard of downgrading on children's GPA in Gymnasium, parental education, and their interaction (Hypotheses $4 a$ and $4 b$ ).

In Hypotheses $3 \mathrm{a}$ and $3 \mathrm{~b}$ (catch-up mechanism), the outcome of interest is not the hazard of downgrading but the GPA in Gymnasium. We estimate a linear mixed model with random intercept to account for the repeated measurements of children's GPA. Here, we regress children's GPA in Gymnasium on children's academic preparedness, parental education, and their interaction.

In all models, we use linear and quadratic terms for children's competence scores to capture potential non-linear effects. We present marginal predicted probabilities for the results of the survival analyses and marginal predicted values for the linear mixed models to ease interpretation.

\section{Results}

\subsection{Selection into the Gymnasium}

The subset of children who attend the Gymnasium are a selective group of all children in the tracked secondary schools (see Table 1). About $30 \%$ of the children in our analysis sample have parents with tertiary education ${ }^{5}$ but in the subset of children in Gymnasium, it is $44 \%$. The average competence score among children in Gymnasium is more than half of a standard

\footnotetext{
${ }^{5}$ Children with high parental education are overrepresented in NEPS due to selective participation in survey. In the German micro census, only in $22.9 \%$ of the children between 10 and 14 years have parents with tertiary education (RDC of the Federal Statistical Office and Statistical Offices of the Federal States, Mikrozensus 2012, own calculations). Yet, we obtain the same substantial results when correcting for this with weights.
} 
deviation (SD) higher than among all children. In general, the competence scores that are standardized to all children in the $5^{\text {th }}$ grade, are shifted upwards when only looking at children who attend a Gymnasium. For example, $31 \%$ of all children are 1.0 SD or more below the average of all children. In contrast, only 3\% of the children in Gymnasium are 1.0 SD or more below the average of all children.

Moreover, among the subset of children in Gymnasium, we also see a smaller association between parental education and competence scores than among all children in the tracked secondary schools. When considering all children, the average competence scores of children whose parents have high education are 0.63 SD $(\mathrm{p}<0.001)$ higher than for children whose parents have less education. In contrast, in the subset of children in Gymnasium, average competence scores of children with highly educated parents are only $0.28 \mathrm{SD}(\mathrm{p}<0.001)$ higher. Hence, in this selective sample, it is all but clear that we will observe a CA of children with low academic preparedness but high parental education.

[Table 1 about here]

\subsection{Descriptive statistics - average rate of downgrading}

Of the 2,371 children who attended a Gymnasium in the $5^{\text {th }}$ grade in $2010,78.3 \%$ are still attending a Gymnasium by the end of $9^{\text {th }}$ grade, $13.5 \%$ have downgraded to another track $(7.7 \%$ to Realschule, $0.2 \%$ to Hauptschule, $5.2 \%$ to schools without tracking or with multiple tracks), and $8.2 \%$ have left the survey. Translated to cause-specific hazards, this means that, on average, $2.9 \%$ of children who attend the Gymnasium in a given academic year will have downgraded to another track until the next academic year, $1.8 \%$ of children will leave the survey, and $95.3 \%$ will still attend the Gymnasium.

[Table 2 about here]

\subsection{Which children downgrade to other tracks?}

In the next step, we employ discrete-time competing-risk survival analysis to evaluate how this average hazard rate of downgrading is related to children's academic preparedness and parental education. The upper part of Figure 3 shows the predicted hazards of downgrading by children's average competence score (on the $\mathrm{x}$-axis) and parental education. ${ }^{6}$ The solid blue line shows predicted hazards for children of parents with a tertiary degree, the dash-dotted red line the

\footnotetext{
${ }^{6}$ The regression coefficients that have been used to make predictions for Figures 3-6 are available in the supplementary materials $\mathrm{C}$. Tables with the predicted values and p-values are available in the supplementary materials D.
} 
predicted hazards for children whose parents have lower education. The transparent areas around the blue and red lines indicate the 95\%-confidence intervals. As a reference, the dashed black line shows the average hazard of downgrading (2.9\%). The lower part of Figure 3 shows a histogram of the distribution of competence scores of the children in Gymnasium to show more clearly in which range of the competence scores differences emerge.

There are large differences in the hazard of downgrading by children's academic preparedness, supporting Hypothesis 1a. Children with low academic preparedness have a much higher risk of downgrading. For example, children with a competence score of -1.0 SD (which puts them into the lowest 3\% among the children in Gymnasium; see Table 2 and the lower part of Figure 3) have a hazard of $8.8 \%$ - three times as large as the average hazard of downgrading. Children with average competence scores of 1.5 SD or higher (which puts them in the top $13 \%$ among the children in Gymnasium) have an average hazard of $1.4 \%$ or less - less than half of the average hazard.

Moreover, children with highly educated parents are generally less likely to downgrade from Gymnasium. The average hazard of children with highly educated parents is $2.5 \%$ compared to $3.2 \%$ among children of less educated parents ( $p$-value of the difference $=0.035$ ).

As stated in Hypothesis 1b, high parental education can compensate for a low academic preparedness. Among the children with competence scores of 0.0 or higher, the advantages for children of highly educated parents are small (hazards differ by $0.3 \%$ to $0.5 \%$ ) and not statistically significant (all p>0.20). However, among the children with a competence score lower than 0.0 (the bottom 25\% of children in Gymnasium), there are more pronounced differences by parental education. For example, among the children with a competence score of $-0.5 \mathrm{SD}$, the hazard of children of highly educated parents is $4.5 \%$, while it is $6.2 \%$ among children of less educated parents $(\mathrm{p}=0.044)$. Gaps by parental education are even larger among children with lower competence scores, but results are imprecise due to the low number of children with very low competence scores in Gymnasium.

[Figure 3 about here]

\subsection{Can the difference in risk of downgrading be attributed to performance on the academic track?}

Next, we evaluate whether differences in the school performance in Gymnasium explain the differences by academic preparedness and parental education in the hazard of downgrading. To ease interpretation, we present the difference in hazard rate by parental education over the 
distribution of competence scores in Figure 4 instead of presenting predicted hazards for high and low education as in Figure 3. The blue points are based on the same regression model as the results in Figure 3, again showing the compensatory advantage of high parental education for low competence scores. We then estimate a second model in which we add GPA in Gymnasium. Thereby, we can decompose the total difference by parental education into a part that can be attributed to differences in the GPA in Gymnasium (green triangles) and a remaining part that cannot be attributed to GPA in Gymnasium (red diamonds).

As expected, the differences in hazard rate are partially mediated by GPA in Gymnasium. However, the indirect effects are small. In absolute terms, the indirect effects of parental education via GPA in Gymnasium are larger among the children with low competence scores. For instance, among children with a competence score of -1.0 SD, the hazard of downgrading is $3.6 \%$ lower for children with high parental education $(\mathrm{p}=0.069) .0 .52$ percentage points of this difference by parental education can be attributed to children's GPA in Gymnasium ( $\mathrm{p}=0.191$; see Table D2 in the supplementary materials) and 3.05 percentage points of this difference cannot be attributed to GPA $(\mathrm{p}=0.087)$. In contrast, among the children with a competence score of $0.0 \mathrm{SD}$, only 0.19 percentage points $(\mathrm{p}=0.006)$ of the difference in the hazard rate by parental education can be attributed to GPA in Gymnasium, and only 0.07 percentage points $(\mathrm{p}=0.080)$ among the children with a competence score of $1.0 \mathrm{SD} .^{7}$

However, the relative contribution of the GPA in Gymnasium to differences by parental education is larger in the middle of the distribution (competence scores between 0.0 and 1.5 $\mathrm{SD}$ ) than at the bottom of the distribution (competence scores lower than 0.0). For example, among children with a competence score of $-1.0 \mathrm{SD}$, the GPA in Gymnasium accounts for $14.5 \%$ of the differences by parental education but $21.5 \%$ among children with a competence score of 1.0 SD. Thus, the results do not support our Hypothesis 2 that the CA in the hazard of downgrading can be attributed to GPA in Gymnasium.

Average differences (not shown) further suggest that GPA in Gymnasium nevertheless mediates the separate differences in downgrading hazard by parental education and academic preparedness. Differences in the GPA account for 1.1 percentage points ( $\mathrm{p}$-value $<0.001)$ of the $7.4 \%$ difference in the hazard rate between children with a competence score of -1.0 SD and 1.5 SD. Thus, $15.5 \%$ of the total difference by academic pareparedness are mediated by GPA

\footnotetext{
${ }^{7}$ Standard errors and p-values of indirect effects are estimated with 500 bootstrap samples.
} 
in Gymnasium. Likewise, 0.11 percentage points of the of the $0.76 \%$ (thus, $14.0 \%$ mediated) average difference by parental education can be attributed to GPA in Gymnasium $(p=0.022)$.

[Figure 4 about here]

\subsection{Do children catch up academically?}

Children with high parental education may still be able to catch-up academically, even if this better performance in Gymnasium does not translate into a lower risk of downgrading. Thus, next, we test whether children with low academic preparedness, but high parental education are more likely to catch up academically (see Figure 5). If this is the case, we should observe larger differences in GPA in Gymnasium by parental education among children with low academic preparedness than among children with high academic preparedness.

As expected, there are vast differences in the current GPA by academic preparedness (supporting Hypothesis 3a). The GPA of children with the lowest competence scores is about 1.0 points worse than the GPA of children with the highest competence scores $(\mathrm{p}<0.001)$. Moreover, the average GPA of children with highly educated parents is 0.11 points higher than the average GPA of children with less educated parents $(\mathrm{p}<0.001)$.

However, we do not find support for our Hypothesis $3 b$ that the association between academic preparedness and performance in Gymnasium is weaker for children of highly educated parents. Instead, the gaps in GPA are small among children with low academic preparedness and slightly larger among children with middle or high levels of academic preparedness. For example, the difference in GPA in Gymnasium by parental education is 0.04 among children with a competence score of $-1.0 \mathrm{SD}$ ( $\mathrm{p}=0.641), 0.13$ among children with a competence score of 1.0 $\mathrm{SD}(\mathrm{p}<0.001)$, and 0.11 among children with a competence score of $2.0 \mathrm{SD}(\mathrm{p}=0.081)$.

[Figure 5 about here]

\subsection{Are children with high parental education more likely to stay in Gymnasium despite having bad grades?}

Lastly, we test whether children with highly educated parents are less likely to downgrade even when showing the same poor performance in Gymnasium (carry-on mechanism). Figure 6 shows the predicted hazard of downgrading by the GPA in Gymnasium, moderated by parental education. 
As expected, children with a good performance in Gymnasium are less likely to downgrade, supporting Hypothesis 4a. The children with the worst GPA (4.0-6.0) ${ }^{8}$ have a hazard of downgrading of $6.3 \%$ - more than twice as high as the average hazard (2.9\%) and about four times larger than the hazard of children with the best GPAs (1.6\%; GPA of 1.0-1.5).

However, contrary to our Hypothesis 4b, we do not find that the association between the GPA in Gymnasium and the hazard of downgrading is weaker for children of highly educated parents. Among the children with very good performance (GPA of 1.0-1.5) and among children with a GPA of 3.5 or worse, there is no relevant difference in the hazard of downgrading by parental education. Instead, we see larger differences by parental education among those children with good to average GPA in Gymnasium. For instance, among the children with a GPA of 2.0, the hazard of downgrading is $1.8 \%$ for children with high parental education but $3.4 \%$ for children with low parental education ( $\mathrm{p}$-value of difference=0.078).

[Figure 6 about here]

\subsection{Ad-hoc analysis of alternative negative experiences}

The GPA in Gymnasium mediates only a small proportion of the differences in downgrading by academic preparedness and parental education and neither the catch-up mechanism nor the carry-on mechanism can explain why high parental education compensates for low academic preparedness in avoiding downgrading. A first explanation for this may be that the assumption that downgrading is only caused by poor performance in Gymnasium is too simplistic. Instead, there may be several other negative school experiences that trigger a downgrade which are related to the level of academic preparedness, but not directly related to children's performance in Gymnasium.

For instance, children with low academic preparedness may have a lower academic selfconcept, may have a harder time connecting with the teacher and classmates, or may only make friends with other low achievers. In turn, these factors may increase the risk of downgrading (Rumberger \& Rotermund, 2012; Stamm, 2010).

The NEPS data allows us to explore some of these alternative negative experiences. We consider children's school-related self-concept, helplessness with the learning content, social integration into the class, perceived connection to the teacher, the proportion of friends who

\footnotetext{
${ }^{8}$ The hazard of downgrading is substantially higher when only considering children with GPA>4.5 or GPA>5.0. However, there are too few cases to evaluate to consider these cases as a separate category in a regression analysis.
} 
aspire to obtain the highest school leaving certificate, and children's predicted probability to succeed in Gymnasium (see supplementary materials E).

Indeed, we find that children with low academic preparedness and low parental education have on average fewer friends who aspire to graduate from Gymnasium, have a lower school-related self-concept, and perceive a lower probability to succeed in Gymnasium. In turn, children with few friends with high aspirations, low school-related self-concept and low perceived probability of success are more likely to downgrade. When considering these additional mediators, we can explain about half of the differences in downgrading by parental education. However, we still cannot explain why there are larger differences by parental education among children with low academic preparedness. Just like for the GPA in Gymnasium, we again see that children of parents with high education are less likely to have these negative experiences but a high parental education neither breaks the link between a low academic preparedness and these experiences nor do we see that high parental education breaks the link between these intervening negative experiences and the hazard of downgrading.

\subsection{Robustness checks}

As discussed in the methods section, we could have chosen alternative measures for the main concepts: academic preparedness (teacher's recommendation or GPA in primary school) and parental SES (occupational class). Therefore, we conducted a robustness analysis to evaluate whether we would have drawn the same conclusions with these alternative operationalizations.

We also find a CA of high parental education for a low academic preparedness when measuring academic preparedness as the average GPA in the last year of primary school (see supplementary materials F1). Among children with the best grades in primary school, the difference in the hazard of downgrading by parental education is about $0.6 \%$. Among children with an average or low GPA in primary school, the difference in the hazard is larger than $1.0 \%$. These differences are partially mediated by the GPA in Gymnasium. However, also when using GPA in primary school as a measure of academic preparedness we find no evidence for the catch-up or the carry-on mechanism.

We find no evidence for CA in downgrading when using teacher's track recommendations as a measure of academic preparedness (see supplementary materials F2). Both, for children who got a recommendation and for children who did not get a recommendation for Gymnasium, the difference in the hazard of downgrading by parental education is about $1.0 \%$. 
Moreover, we also find evidence for a $\mathrm{CA}$ in the hazard of downgrading when measuring parental SES as parents' highest EGP (see supplementary materials F3). When comparing children of service-class parents (EGP I and II) to children of working-class parents (EGP IIIb and V-VII), the CA is even more pronounced than when comparing parents with and without tertiary education. Again, a small share of CA is mediated via performance in Gymnasium and there is no evidence for a weaker association between academic preparedness and performance in Gymnasium for service-class children. However, as proposed in the carry-on mechanism, the association between the performance in Gymnasium and the hazard of dropout seems to be less pronounced for service-class children.

\section{Discussion}

In this paper, we make two contribution to the literature on compensatory advantage in educational attainment. First, we evaluate whether high parental education compensates for low academic preparedness (as measured by competence score in reading and mathematics) and reduces the risk of downgrading from the academic track.

We find that the risk of downgrading in a given year is more than six times higher for children who attend the academic track despite having very low competences compared to children with the highest competences. We also find that among children with low competence scores, children with highly educated parents are more likely to stay on the academic track. This advantage by parental education diminishes with increasing competence scores, supporting the claims of the compensatory advantage theory. Parents with high education indeed seem to find ways to compensate for a lack of academic preparedness of their children within academically demanding educational institutions (Contini et al., 2018), although they already make more ambitious educational decisions at the transition into these institutions.

These results imply that two patterns of stratification accumulate: children of highly educated parents do not only make ambitious educational decisions despite below-average performance more often, but they are also more likely to make them work. Our results suggest that the average SES differences in downgrading that have been reported in other studies (e.g., Hillmert \& Jacob, 2010; Schneider, 2008; Tieben \& Wolbers, 2010) can largely be attributed to children with low academic preparedness. In contrast, we find almost no differences in downgrading hazard by parental education among children with high academic preparedness.

Second, we investigate the underlying mechanisms of the compensatory advantage in downgrading. We find that the lower risk of downgrading of children with high parental 
education can partially be attributed to their better performance on the academic track. However, these differences in the performance on the academic track do not explain why the advantage of children with high parental education is much more pronounced among the children with a low academic preparedness (i.e., the CA).

Among children with low academic preparedness, high-SES children may be more likely than low-SES children to catch up academically during secondary school (Schneider \& Linberg, 2021). However, we find no evidence for the idea that the CA in downgrading results from such a catch-up mechanism. Likewise, high parental education does not break the path dependency between a low academic preparedness and other negative experiences that may function as mediators, threatening children's success on the academic track. Neither do we find that the CA in downgrading results from children with high parental education reacting differently to bad grades or the other negative experiences that we have evaluated here (the hypothesized carryon mechanism). Our results thus yield no clear support for the notions of resource mobilization (F. Bernardi, 2014; F. Bernardi \& Grätz, 2015; Schneider \& Linberg, 2021) and differing responsiveness to ability information (F. Bernardi \& Cebolla-Boado, 2014b; F. Bernardi \& Triventi, 2020; Holm et al., 2019) in the context of downgrading.

Instead, our results imply that the CA of high parental education for a low academic preparedness may largely result from a purely 'mechanical' effect: We observe the CA of high parental education for a low academic preparedness because only when academic preparedness is low, there is a considerable risk of downgrading which parental education can compensate for. Children with high parental education enjoy certain advantages regardless of their academic preparedness, which reduces their risk of downgrading. Because downgrading implies reversing a previous decision, it generally occurs only in the case of detrimental grades and only when children see almost no graduation chance anymore. The average advantages by parental education will push some of the most jeopardized children over the threshold (e.g., for GPA), preventing them from downgrading. In contrast, similarly small differences by parental education among the children with high academic preparedness are less relevant for track changes: Children with good or average performance will rarely downgrade anyways.

In addition to mechanisms directly related to secondary school performance, the overall SES advantages in downgrading risk may also be indicative of unobserved interaction processes between parents and school personnel, in which higher-SES parents are usually more involved and more successful (Dumont et al., 2019; Lyken-Segosebe \& Hinz, 2015). Moreover, highSES families may be more likely to enroll their child in a regular Gymnasium instead of a 
Gymnasium class in a comprehensive school. An additional analysis (not reported) showed that downgrading risk is significantly higher for students visiting a Gymnasium class in a comprehensive school than for students in a regular Gymnasium.

Surprisingly, we find that large differences in the hazard of downgrading by academic preparedness remain, even when accounting for children's performance in the academic track. This stands in contrast to the idea that poor academic performance is the main reason for downgrading (Hillmert \& Jacob, 2010; Jacob \& Tieben, 2009). Instead, we find that children with a low academic preparedness are also more likely to downgrade because they have a lower academic self-concept, perceive a lower probability to succeed in Gymnasium, and have fewer friends with high aspirations.

Some limitations must be considered for the interpretation of our results. First, $8 \%$ of children left the survey before the end of the $9^{\text {th }}$ grade and we cannot evaluate whether they have downgraded. We can partially address this problem in the survival analysis by treating 'left survey' as an outcome on its own. Second, the small share of mediation by performance may be due to measurement error. Only German and mathematic grades were measured regularly. However, grades in other subjects like foreign languages, which may be particularly relevant for downgrading (Dittrich, 2014) were not availalbe.Third, our analysis explored differences in the risk of downgrading, but we cannot make any causal claims. Particularly among the children with low academic preparedness, there are probably differences in unobserved characteristics between children with low and high parental education (Mare, 1980).

Despite these limitations, our results suggest that the compensation of high SES for a lack of academic preparedness after academically ambitious decisions leads to further stratification of educational attainment. While we have evaluated it exemplarily for the academic secondary school track in Germany, this mechanism could also apply to all other countries with (betweenschool) tracking in secondary school and tertiary education. Regarding tracking in secondary school, this mechanism will be particularly relevant in all contexts where families have the free choice between tracks (independent of children's academic preparedness) and where the track choice has large consequences for further educational alternatives (e.g., if not all tracks grant eligibility to tertiary education). Moreover, there are likely larger compensatory effects for a lack of academic preparedness in countries with early tracking. Thus, among others, substantial stratification of downgrading from academic tracks may also take place in Austria, Belgium, Luxembourg, the Netherlands, and Italy. Future research should not only evaluate social stratification in enrollment but also evaluate stratification in the risk of downgrading afterwards. 


\section{Literature}

Albrecht, R., Neumann, M., Jansen, M., Becker, M., Maaz, K., \& Baumert, J. (2018). Schulformwechsel im zweigliedrigen Schulsystem: Determinanten für das Nichtbestehen des Probejahres am Gymnasium in Berlin. Zeitschrift für Erziehungswissenschaft, 21(4), 839-865. https://doi.org/10.1007/s11618-018-0810-6

Autorengruppe Bildungsberichterstattung. (2020). Bildung in Deutschland 2020. wbv Media. https://doi.org/10.3278/6001820gw

Bach, M., \& Fischer, M. (2020). Understanding the Response to High-Stakes Incentives in Primary Education. ZEW - Centre for European Economic Research Discussion Paper No. 20-066. https://doi.org/10.2139/ssrn.3736769

Baeriswyl, F., Trautwein, U., Wandeler, C., \& Lüdtke, O. (2010). Wie gut prognostizieren subjektive Lehrerempfehlungen und schulische Testleistungen beim Übertritt die Mathematikund Deutschleistung in der Sekundarstufe I? In J. Baumert, K. Maaz, \& U. Trautwein (Eds.), Bildungsentscheidungen: Zeitschrift für Erziehungswissenschaft Sonderheft 12 | 2009 (pp. 352-372). VS Verlag für Sozialwissenschaften. https://doi.org/10.1007/978-3-531-92216-4_15

Bernardi, F. (2012). Unequal transitions: Selection bias and the compensatory effect of social background in educational careers. Research in Social Stratification and Mobility, 30(2), 159-174. https://doi.org/10.1016/j.rssm.2011.05.005

Bernardi, F. (2014). Compensatory advantage as a mechanism of educational inequality: A regression discontinuity based on month of birth. Sociology of Education, 87(2), 74-88. https://doi.org/10.1177/0038040714524258

Bernardi, F., \& Cebolla-Boado, H. (2014a). Social class and school performance as predictors of educational paths in Spain. Revista Española de Investigaciones Sociologicas, 146(1), 3-22. 
Bernardi, F., \& Cebolla-Boado, H. (2014b). Previous School Results and Social Background: Compensation and Imperfect Information in Educational Transitions. European Sociological Review, 30(2), 207-217. https://doi.org/10.1093/esr/jct029

Bernardi, F., \& Grätz, M. (2015). Making Up for an Unlucky Month of Birth in School: Causal Evidence on the Compensatory Advantage of Family Background in England. Sociological Science, 2, 235-251. https://doi.org/10.15195/v2.a12

Bernardi, F., \& Triventi, M. (2020). Compensatory advantage in educational transitions: Trivial or substantial? A simulated scenario analysis. Acta Sociologica, 63(1), 40-62. https://doi.org/10.1177/0001699318780950

Bernardi, M., Bratti, M., \& De Simone, G. (2014). 'I Wish I Knew ... '-Misperceived Ability, School Track Counseling Services and Performances in Upper Secondary Education (IZA Discussion Paper No. 7940). Social Science Research Network. https://papers.ssrn.com/abstract=2396435

Bittmann, F. (2021). Academic track mismatch and the temporal development of well-being and competences in German secondary education. Vienna Yearbook of Population Research, 19(1).

Blossfeld, H.-P., \& von Maurice, J. (2011). Education as a lifelong process. Zeitschrift für Erziehungswissenschaft, 14(2), 19-34. https://doi.org/10.1007/s11618-011-0179-2

Boudon, R. (1974). Education, Opportunity, and Social Inequality: Changing Prospects in Western Society. Wiley.

Breen, R., \& Goldthorpe, J. H. (1997). Explaining Educational Differentials: Towards a Formal Rational Action Theory. Rationality and Society, 9(3), 275-305. https://doi.org/10.1177/104346397009003002

Bukodi, E., Goldthorpe, J. H., \& Zhao, Y. (2021). Primary and secondary effects of social origins on educational attainment: New findings for England. British Journal of Sociology. https://doi.org/10.1111/1468-4446.12845 
Burgette, L. F., \& Reiter, J. P. (2010). Multiple Imputation for Missing Data via Sequential Regression Trees. American Journal of Epidemiology, 172(9), 1070-1076. https://doi.org/10.1093/aje/kwq260

Carneiro, P., Løken, K. V., \& Salvanes, K. G. (2015). A flying start? Maternity leave benefits and long-run outcomes of children. Journal of Political Economy, 123(2), 365-412.

Contini, D., Cugnata, F., \& Scagni, A. (2018). Social selection in higher education. Enrolment, dropout and timely degree attainment in Italy. Higher Education, 75(5), 785-808. https://doi.org/10.1007/s10734-017-0170-9

De Witte, K., \& Rogge, N. (2013). Dropout from secondary education: All's well that begins well. European Journal of Education, 48(1), 131-149.

Ditton, H. (2013). Bildungsverläufe in der Sekundarstufe. Ergebnisse einer Längsschnittstudie zu Wechseln der Schulform und des Bildungsgangs. Zeitschrift für Pädagogik, 59(6), 887-911.

Dittrich, E. (2014). Underachievement leading to downgrading at the highest level of secondary education in the Netherlands: A longitudinal case study. Roeper Review, 36(2), 104 113.

Dräger, J., \& Müller, N. (2020). Wealth Stratification in the Early School Career in Germany. Research in Social Stratification and Mobility, 67, 100483. https://doi.org/10.1016/j.rssm.2020.100483

Dumont, H., Klinge, D., \& Maaz, K. (2019). The many (subtle) ways parents game the system: Mixed-method evidence on the transition into secondary-school tracks in germany. $\begin{array}{llll}\text { Sociology of } & \text { Education, } & \text { 92(2), }\end{array}$ https://doi.org/10.1177\%2F0038040719838223

Dustmann, C., Puhani, P. A., \& Schönberg, U. (2017). The Long-term Effects of Early Track Choice. The Economic Journal, 127(603), 1348-1380. https://doi.org/10.1111/ecoj.12419 
Erikson, R., Goldthorpe, J. H., Jackson, M., Yaish, M., \& Cox, D. R. (2005). On class differentials in educational attainment. Proceedings of the National Academy of Sciences, 102(27), 9730-9733. https://doi.org/10.1073/pnas.0502433102

Ermisch, J., \& Francesconi, M. (2013). The effect of parental employment on child schooling. Journal of Applied Econometrics, 28(5), 796-822.

Gil-Hernández, C. J. (2021). The (unequal) interplay between cognitive and noncognitive skills in early educational attainment. American Behavioral Scientist, 0002764221996764.

Grätz, M., \& Bernardi, F. (2017). Parental responses to disadvantageous life events: The month of birth penalty in England. In J. Erola \& E. Kilpi-Jakonen (Eds.), Social inequality across the generations (pp. 68-86). Edward Elgar Publishing.

Grätz, M., \& Wiborg, Ø. N. (2020). Reinforcing at the top or compensating at the bottom? Family background and academic performance in Germany, Norway, and the United States. European Sociological Review, 36(3), 381-394.

Herbaut, E. (2020). Overcoming failure in higher education: Social inequalities and compensatory advantage in dropout patterns. Acta Sociologica, 1-20. https://doi.org/10.1177/0001699320920916

Hillmert, S., \& Jacob, M. (2010). Selections and social selectivity on the academic track: A lifecourse analysis of educational attainment in Germany. Research in Social Stratification and Mobility, 28(1), 59-76. https://doi.org/10.1016/j.rssm.2009.12.006

Hoffmann, L., Stanat, P., Maaz, K., \& Klemm, K. (2019). Kompetenzen von Schülerinnen und Schülern an Schulen in privater und öffentlicher Trägerschaft. Kölner Zeitschrift für Soziologie und Sozialpsychologie, 71(3), 385-408.

Holm, A., Hjorth-Trolle, A., \& Jæger, M. M. (2019). Signals, educational decision-making, and inequality. European Sociological Review, 35(4), 447-460. https://doi.org/10.1093/esr/jcz010 
Huang, M.-H. (2020). Compensatory advantage and the use of out-of-school-time tutorials: A cross-national study. Research in Social Stratification and Mobility, 66, 100472. https://doi.org/10.1016/j.rssm.2020.100472

Iatridis, T., \& Fousiani, K. (2009). Effects of status and outcome on attributions and just-world beliefs: How the social distribution of success and failure may be rationalized. Journal of Experimental Social Psychology, 45(2), 415-420. https://doi.org/10.1016/j.jesp.2008.12.002

Jackson, M. (2013). Determined to Succeed? Performance versus Choice in Educational Attainment. Stanford University Press.

Jacob, M., \& Tieben, N. (2009). Social selectivity of track mobility in secondary schools: A comparison of intra-secondary transitions in Germany and the Netherlands. European Societies, 11(5), 747-773.

Klapproth, F., Krolak-Schwerdt, S., Glock, S., Böhmer, M., \& Martin, R. (2013). The predictive validity of school placement decisions in Luxembourg: A comparison between track continuation rates and test scores. Swiss Journal of Educational Research, 35(2), 319346. https://doi.org/10.24452/sjer.35.2.4914

Kloosterman, R., \& de Graaf, P. M. (2010). Non-promotion or enrolment in a lower track? The influence of social background on choices in secondary education for three cohorts of Dutch pupils. Oxford Review of Education, 36(3), 363-384. https://doi.org/10.1080/03054981003775244

Lohmann, H., \& Groh-Samberg, O. (2010). Akzeptanz von Grundschulempfehlungen und Auswirkungen auf den weiteren Bildungsverlauf / Acceptance of Secondary School Track Recommendations and Their Effects on Educational Achievement. Zeitschrift für Soziologie, 39(6). https://doi.org/10.1515/zfsoz-2010-0603

Lucas, S. R. (2009). Stratification theory, socioeconomic background, and educational attainment: A formal analysis. Rationality and Society, 21(4), 459-511. 
Lyken-Segosebe, D., \& Hinz, S. E. (2015). The politics of parental involvement: How opportunity hoarding and prying shape educational opportunity. Peabody Journal of Education, 90(1), 93-112.

Mare, R. D. (1980). Social Background and School Continuation Decisions. Journal of the American Statistical Association, $\quad$ 75(370), 295-305. https://doi.org/10.1080/01621459.1980.10477466

McNeal Jr, R. B. (1999). Parental involvement as social capital: Differential effectiveness on science achievement, truancy, and dropping out. Social Forces, 78(1), 117-144.

Neugebauer, M. (2010). Bildungsungleichheit und Grundschulempfehlung beim Übergang auf das Gymnasium: Eine Dekomposition primärer und sekundärer Herkunftseffekte / Educational Inequality and Teacher Recommendations at the Transition to Upper Secondary School: A Decomposition of Primary and Secondary Effects of Social Origin. Zeitschrift für Soziologie, 39(3). https://doi.org/10.1515/zfsoz-2010-0303

Neugebauer, M., Reimer, D., Schindler, S., \& Stocké, V. (2013). Inequality in Transitions to Secondary School and Tertiary Education in Germany. In M. Jackson (Ed.), Determined to Succeed? Performance versus Choice on Educational Attainment (pp. 56-88). Stanford University Press.

Neugebauer, M., \& Schindler, S. (2012). Early transitions and tertiary enrolment: The cumulative impact of primary and secondary effects on entering university in Germany. Acta Sociologica, 55(1), 19-36. https://doi.org/10.1177/0001699311427747

Neumann, I., Duchhardt, C., Grüßing, M., Heinze, A., Knopp, E., \& Ehmke, T. (2013). Modeling and assessing mathematical competence over the lifespan. Journal for Educational Research Online, 5(2), 80-109.

Park, H., Byun, S., \& Kim, K. (2011). Parental involvement and students' cognitive outcomes in Korea: Focusing on private tutoring. Sociology of Education, 84(1), 3-22. 
Prentice, R. L., Kalbfleisch, J. D., Peterson, A. V., Farewell, V. T., \& Breslow, N. E. (1978). The Analysis of Failure Times in the Presence of Competing Risks. Biometrics, 34(4), 541-554. https://doi.org/10.2307/2530374

Rubin, D. B. (1987). Multiple Imputation for Nonresponse in Surveys. John Wiley \& Sons.

Rumberger, R. W., \& Rotermund, S. (2012). The relationship between engagement and high school dropout. In Handbook of research on student engagement (pp. 491-513). Springer.

Scharenberg, K., Gröhlich, C., \& Bos, W. (2009). Schulformwechsel bei konformer und nichtkonformer Bildungsentscheidung für das Gymnasium. In C. Röhner, C. Henrichwark, \& M. Hopf (Eds.), Europäisierung der Bildung (pp. 263-267). VS Verlag für Sozialwissenschaften.

Schneider, T. (2008). Social Inequality in Educational Participation in the German School System in a Longitudinal Perspective: Pathways into and out of the most Prestigious School Track. European Sociological Review, 24(4), 511-526. https://doi.org/10.1093/esr/jen017

Schneider, T., \& Linberg, T. (2021). Development of socio-economic gaps in children's language skills in Germany. Longitudinal and Life Course Studies.

Stamm, M. (2010). Dropouts am Gymnasium. Zeitschrift für Erziehungswissenschaft, 13(2), 273-291. https://doi.org/10.1007/s11618-010-0121-z

Stienstra, K., Maas, I., Knigge, A., \& Schulz, W. (2020). Resource compensation or multiplication? The interplay between cognitive ability and social origin in explaining educational attainment. European Sociological Review. https://doi.org/10.1093/esr/jcaa054

Tieben, N., \& Wolbers, M. (2010). Success and failure in secondary education: Socio-economic background effects on secondary school outcome in the Netherlands, 1927-1998. 
British Journal of Sociology of Education, 31(3), 277-290. https://doi.org/10.1080/01425691003700516

Tiedemann, J., \& Billmann-Mahecha, E. (2010). Wie erfolgreich sind Gymnasiasten ohne Gymnasialempfehlung? Zeitschrift für Erziehungswissenschaft, 13(4), 649-660. https://doi.org/10.1007/s11618-010-0146-3

Traini, C., Kleinert, C., \& Schindler, S. (2021). Does tracking really affect labour-market outcomes in the long run? Estimating the long-term effects of secondary-school tracking in West Germany. Longitudinal and Life Course Studies. https://doi.org/10.1332/175795920X16062248132253

Winkler, O. (2017). Aufstiege und Abstiege im Bildungsverlauf. Springer Fachmedien Wiesbaden. https://doi.org/10.1007/978-3-658-15726-5 


\section{Figures}

Figure 1. Conceptual model: Compensatory advantage in enrollment vs. compensatory advantage in track changes

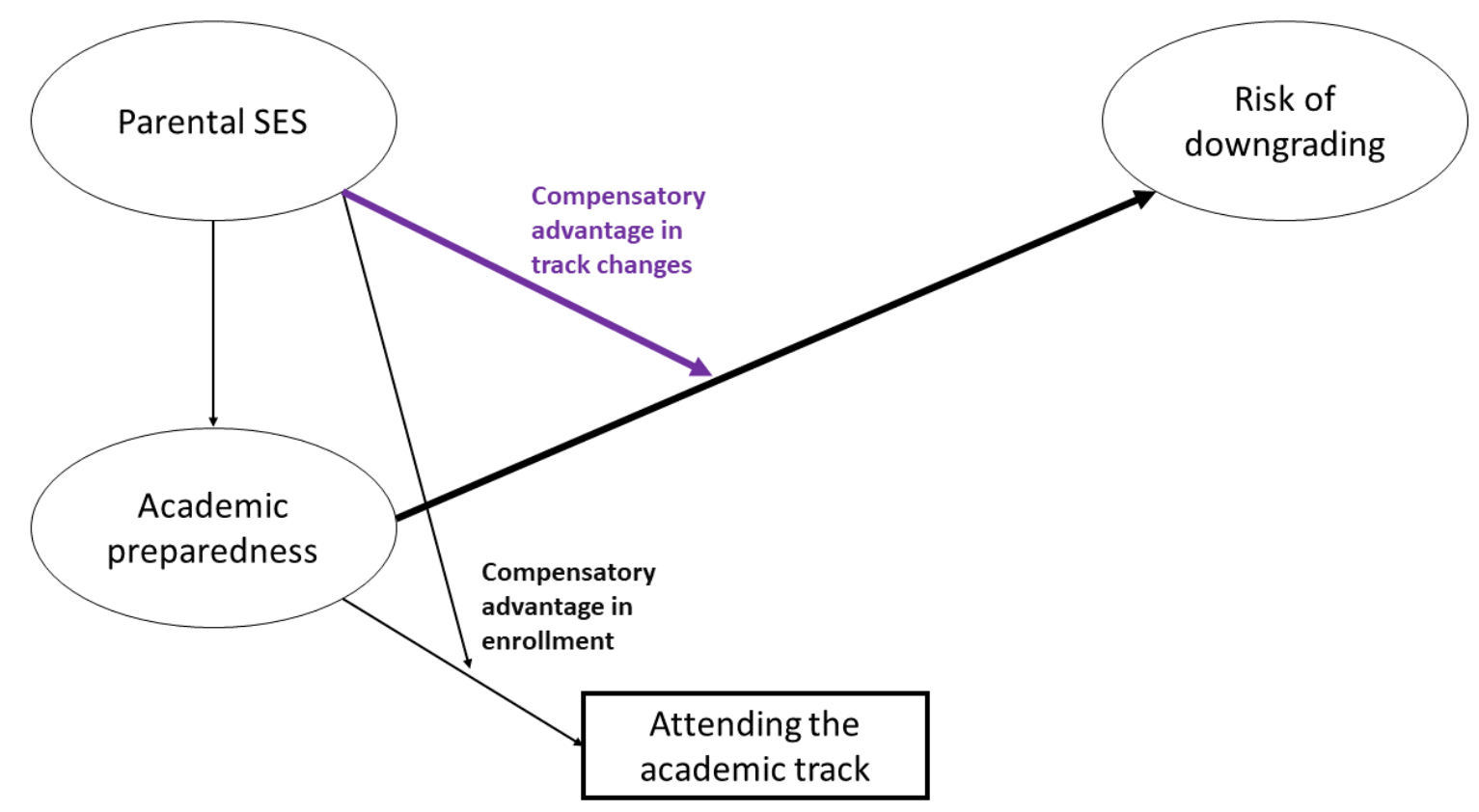


Figure 2. Conceptual model: Compensation for low academic preparedness by parental SES

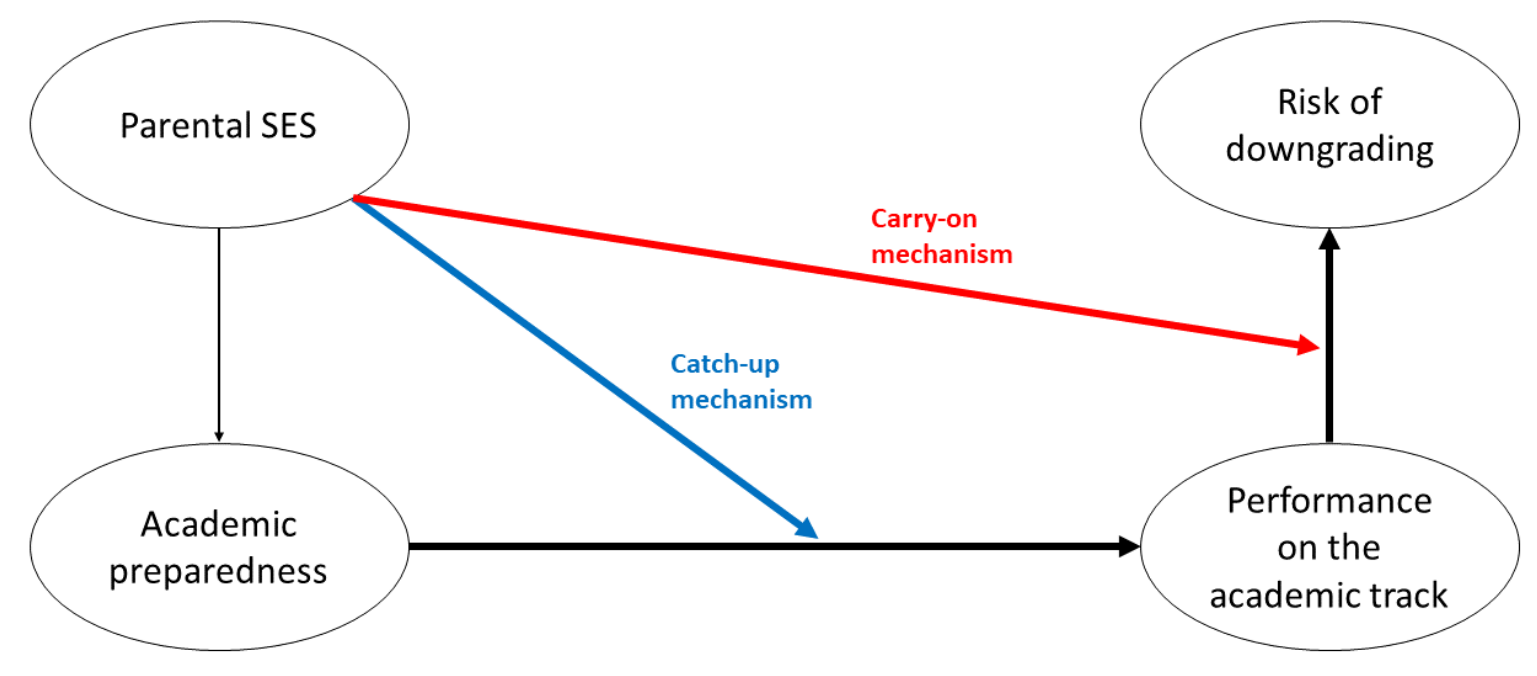


Figure 3: Predicted hazard of downgrading by competence score and parental education
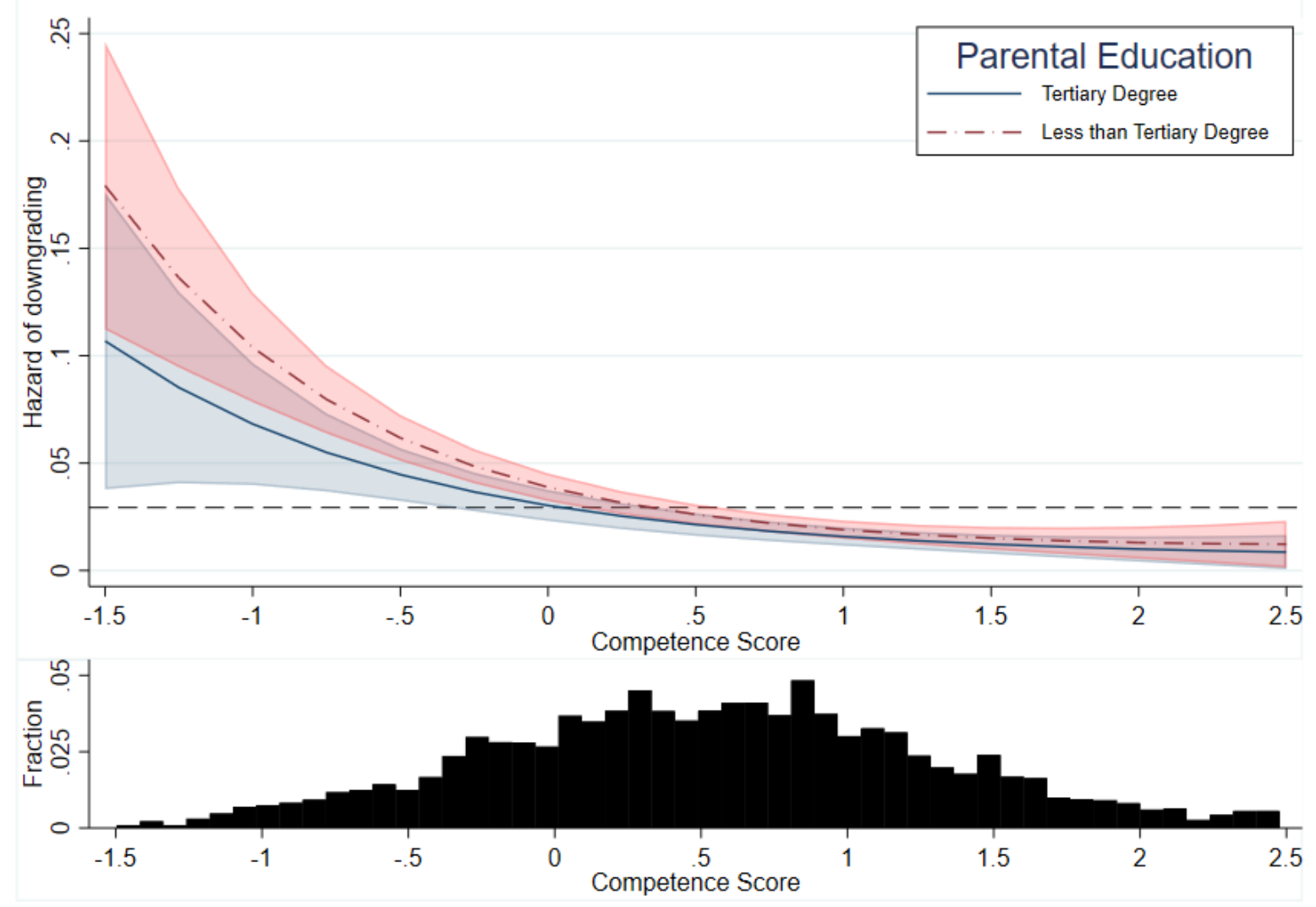

Note. Predicted hazards based on competing-risk survival models. The underlying regression estimates are available in the supplementary materials $\mathrm{C} 1$; the exact predicted hazard rates are available in the supplementary materials D1. 
Figure 4: Mediation of the difference in the hazard of downgrading by competence score and parental education via performance (GPA in Gymnasium)
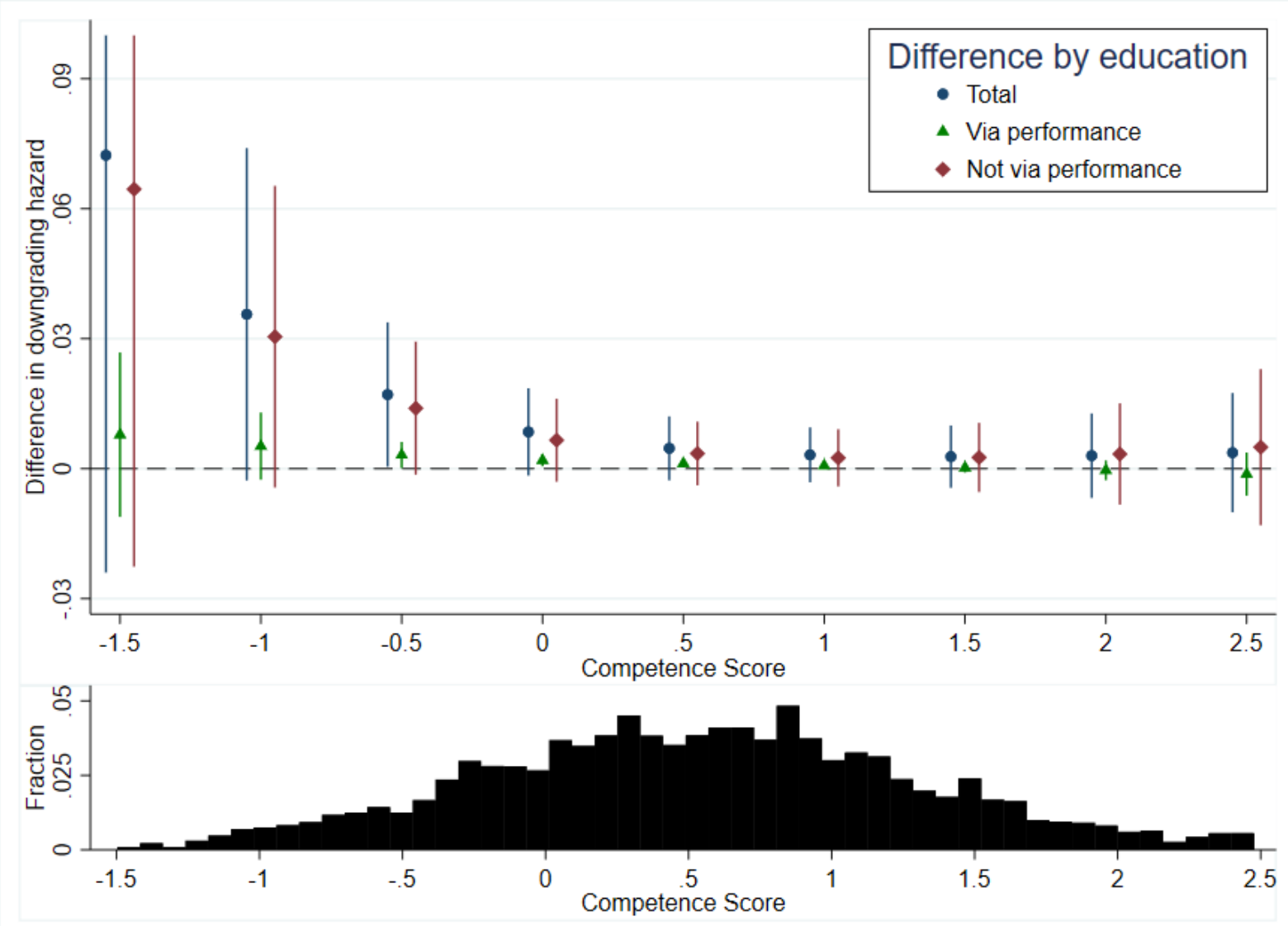

Note. Predicted hazards based on competing-risk survival models. The underlying regression estimates are available in the supplementary materials $\mathrm{C} 1$; the exact predicted hazard rates are available in the supplementary materials D2. 
Figure 5: Predicted GPA in Gymnasium by competence score and parental education
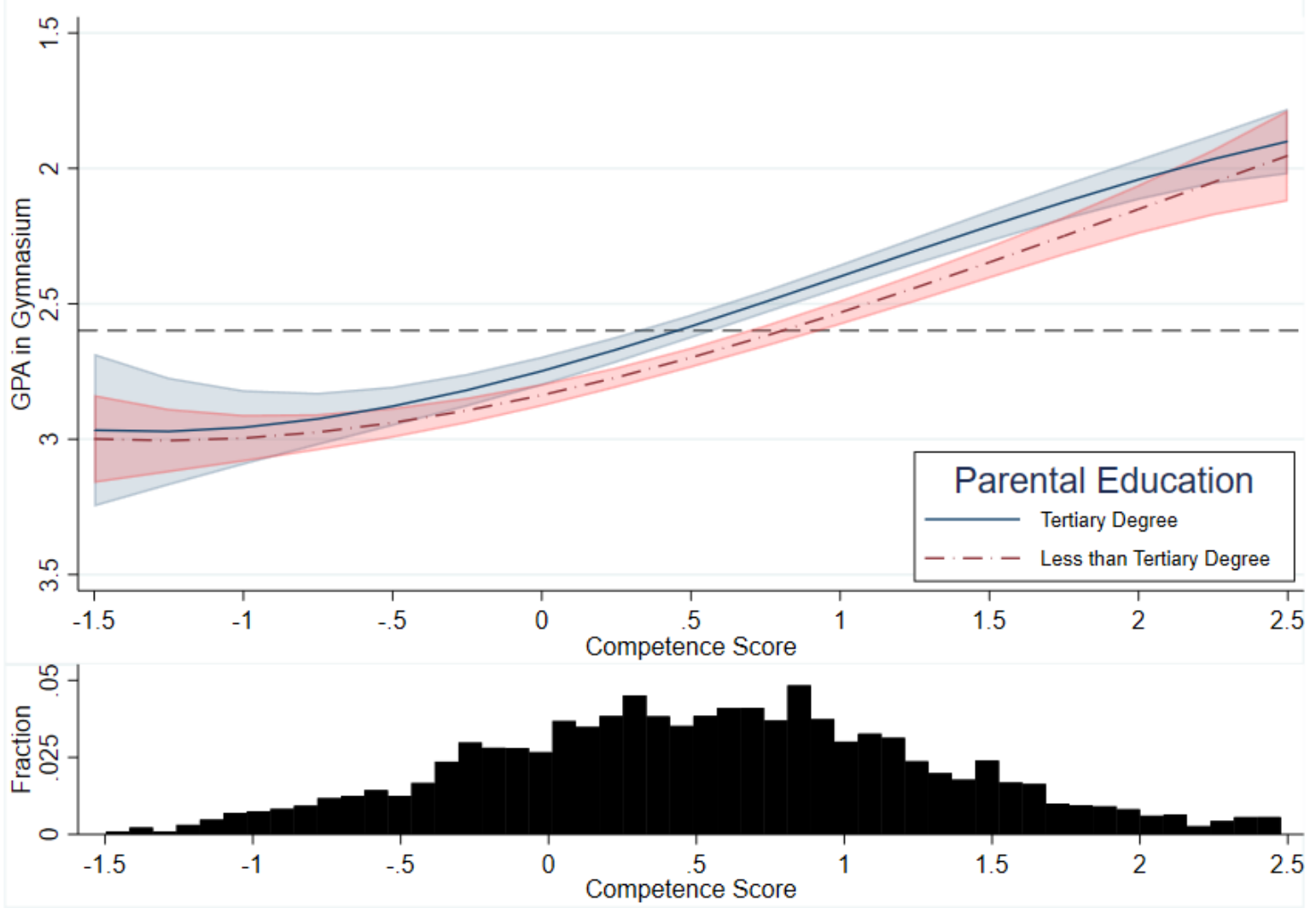

Note. Predicted values based on linear mixed models. The underlying regression estimates are available in the supplementary materials $\mathrm{C} 2$; the exact predicted values are available in the supplementary materials D3. Grades in Germany range from 1 'very good' to 6 'insufficient'. 
Figure 6: Predicted hazard of downgrading by GPA in Gymnasium and parental education

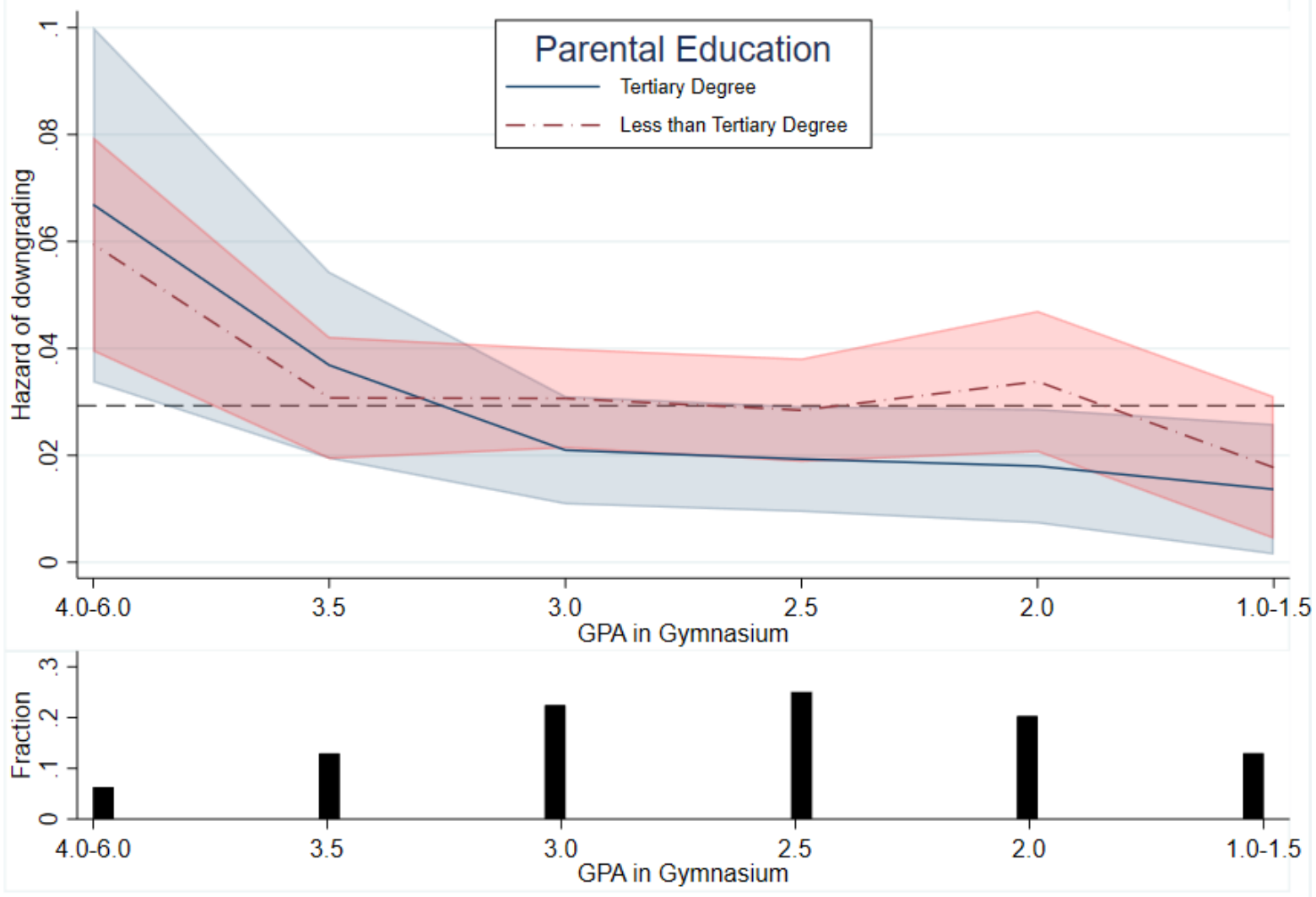

Note. Predicted hazards based on competing-risk survival models. The underlying regression estimates are available in the supplementary materials C3; the exact predicted hazard rates are available in the supplementary materials D4. Grades in Germany range from 1 'very good' to 6 'insufficient'. 


\section{Tables}

Table 1. Descriptive statistics by attended track in $5^{\text {th }}$ grade

\begin{tabular}{|c|c|c|c|c|c|c|}
\hline & \multicolumn{2}{|c|}{ Full sample } & \multicolumn{2}{|c|}{ Gymnasium } & \multicolumn{2}{|c|}{ Other tracks } \\
\hline & $\begin{array}{c}\text { Mean/ } \\
\text { Proportion }\end{array}$ & SE & $\begin{array}{c}\text { Mean/ } \\
\text { Proportion }\end{array}$ & SE & $\begin{array}{c}\text { Mean/ } \\
\text { Proportion }\end{array}$ & SE \\
\hline \multicolumn{7}{|l|}{ Academic preparedness } \\
\hline Competence Score & 0.00 & 1.00 & 0.56 & 0.81 & -0.54 & 0.86 \\
\hline Share lower than -2.0 & 0.02 & & 0.00 & & 0.04 & \\
\hline Share lower than -1.5 & 0.07 & & 0.00 & & 0.14 & \\
\hline Share lower than -1.0 & 0.17 & & 0.03 & & 0.31 & \\
\hline Share lower than -0.5 & 0.31 & & 0.09 & & 0.53 & \\
\hline Share lower than 0.0 & 0.49 & & 0.24 & & 0.73 & \\
\hline Share lower than 0.5 & 0.69 & & 0.48 & & 0.89 & \\
\hline Share lower than 1.0 & 0.84 & & 0.72 & & 0.96 & \\
\hline Share lower than 1.5 & 0.93 & & 0.88 & & 0.99 & \\
\hline Share lower than 2.0 & 0.98 & & 0.96 & & 1.00 & \\
\hline German mark in $4^{\text {th }}$ grade & 2.33 & 0.88 & 1.88 & 0.65 & 2.78 & 0.84 \\
\hline Math mark in $4^{\text {th }}$ grade & 2.28 & 0.94 & 1.84 & 0.67 & 2.72 & 0.96 \\
\hline \multicolumn{7}{|l|}{ Recommendation for } \\
\hline Gymnasium & 0.48 & & 0.84 & & 0.12 & \\
\hline \multicolumn{7}{|l|}{ Parental SES } \\
\hline \multicolumn{7}{|l|}{ Parents have higher } \\
\hline EGP: Working Class & 0.25 & & 0.13 & & 0.37 & \\
\hline EGP: Mixed Class & 0.19 & & 0.15 & & 0.22 & \\
\hline EGP: Service Class & 0.56 & & 0.71 & & 0.42 & \\
\hline \multicolumn{7}{|l|}{ Control Variables } \\
\hline West Germany & 0.91 & & 0.91 & & 0.91 & \\
\hline Birth month & 479.46 & 6.16 & 481.32 & 4.87 & 477.64 & 6.71 \\
\hline Child is a girl & 0.48 & & 0.49 & & 0.47 & \\
\hline Both biological parents & 0.71 & & 0.80 & & 0.63 & \\
\hline Single parents & 0.10 & & 0.08 & & 0.13 & \\
\hline Stepfamily & 0.10 & & 0.08 & & 0.13 & \\
\hline Other constellation & 0.08 & & 0.04 & & 0.12 & \\
\hline Native & 0.76 & & 0.79 & & 0.73 & \\
\hline 1. Generation & 0.04 & & 0.03 & & 0.05 & \\
\hline 2. Generation & 0.20 & & 0.18 & & 0.22 & \\
\hline Number of siblings & 1.22 & 1.05 & 1.15 & 0.95 & 1.29 & 1.13 \\
\hline Birthyear parents & 1968.72 & 5.46 & 1968.04 & 5.09 & 1969.38 & 5.73 \\
\hline $\begin{array}{l}\text { Difference in competence } \\
\text { score by parental } \\
\text { education }\end{array}$ & -0.64 & 0.03 & -0.29 & 0.04 & -0.33 & 0.06 \\
\hline $\mathrm{N}$ & 4,803 & & 2,371 & & 2,432 & \\
\hline
\end{tabular}


Table 2. Students last survival state (until $9^{\text {th }}$ grade) and cause-specific hazard rates

\begin{tabular}{lccc}
\hline Status & $\mathbf{N}$ & \% & Hazard-rate \\
\hline Downgrade & 321 & 13.5 & 2.9 \\
Left Survey & 194 & 8.2 & 1.8 \\
In Gymnasium & 1,856 & 78.3 & 95.3 \\
\hline
\end{tabular}




\section{Supplementary materials}

\section{A. Detailed Description of the 'Current Track' Variable}

\section{General information:}

The NEPS panel provides information on SC3 children's school careers mainly through a generated variable called "t723080_g1" (current type of school, constructed; hereafter: "NEPSgenerated variable"). The procedures of the NEPS-internal construction of this variable can be obtained from the official NEPS documentation (Bayer, Goßmann, \& Bela, 2014). The general logic was to use parental answers about their children's current school type only. Since this information is not always reliable, parental answers were compared to the child's classmates' parents' answers (using the mode of these answers). Unfortunately, the variable suffers from several problems:

1. High share of missing values ( $30 \%$ in the full sample) because many parents did not participate in the study.

2. Among children enrolled at a Gymnasium in wave 1, almost no later downgrading events are captured in the dataset (see Table A1 below).

3. A lot of information available in different NEPS datasets was not included.

4. The parental surveys were conducted in waves 1-4 and 6 only. In waves 5 and 7-10, the generated values are based on an (undocumented) NEPS-internal procedure using classmates' information, even if neither the child nor their parents participated in the study anymore. It was assumed that most likely the children should still be in the same class. Especially for later waves, we consider this a problematic assumption.

5. For many of the missing observations, it is unclear if the child left the survey for personal reasons or if there is just no information provided by the respondents or if the child left the school system. For our analyses, the distinction between downgrade/dropout and leaving the survey is crucial.

Therefore, we decided to augment the NEPS-generated variable. We combined all the unused information and overwrote unreliable or missing information in the NEPS-generated variable. In the following, we describe the main logic of our augmentation routine.

\section{Data sources and preparation:}

a. Children's interview month in each wave: "SC3_CohortProfile"

For several steps of the reconstruction, we needed to convert spell data into wavespecific information. Therefore, we had to define a key month for each wave. If available, we used the child's month of interview. If unavailable, we used the first month 
of NEPS school children's observation period: Children who did not participate in a certain wave but returned in a later wave, may have been interviewed already in the first month of the observation period of the wave in which she/he was absent. Changes occurring in a later month will hence appear as change between waves at time $t$ and $t+1$.

\section{b. Individual tracking: "SC3_CohortProfile"}

The children surveyed in the NEPS-SC3 were sampled via their current school (NEPS partner schools). When a child left the NEPS partner school, the regular interviews, which were supported by the teachers, could not be conducted anymore. Hence, these children were tracked individually and received special questionnaires. Information by parents or through classmates was unavailable in these cases. The NEPS-generated variable does not make use of this information (variable "tx80232") at all.

\section{c. NEPS-generated variable: "SC3_CohortProfile"}

The NEPS-generated variable "t723080_g1" is reliable only for waves 1-6 and for children still participating in the survey (see "General information"). Therefore, we discarded information from the variable when these two criteria were not met.

\section{d. Parental information (spells): "SC3_spParentSchool"}

This dataset entails parental information on their children's type of school in spell data format. It was surveyed in waves 1-4 and 6. The variable entails a harmonized version of these information in later waves, so we have the most recent information possible available for each child. The information in this dataset provided the basis for the NEPSgenerated variable. Surprisingly, there was a notable number of observations for which we were able to add information from this dataset on top of the NEPS-generated variable. We only used additional information from this dataset for cases which had missing values in the constructed variable even after including individual tracking. At this point, we took the calculated risk that additional parental information may not entirely be accurate.

\section{e. Child information (cross-sectional): "SC3_pTarget"}

This dataset entails information provided by children about their current school track, surveyed from wave 7 onwards (variables "tf1 1404" and "tf1 1405"). This information is not included in the NEPS-generated variable. Some children reported special types of schools. Many of these school were equivalent to Gymnasium, Realschule or 
Hauptschule since they (mainly) lead to one of the three most important degrees (Abitur, Mittlere Reife, Hauptschulabschluss). When the highest possible degree to be obtained from a certain school type was unclear, we chose to recode them as "non-tracked / other":

“Gymnasium": "Technisches Gymnasium", "Wirtschaftsgymnasium” (only leading to Abitur if a second foreign language is chosen), "berufliches reguläres Gymnasium", "Aufbaugymnasium“, "Berufs-“, „Fach-" \& „,erweiterte Oberschule“, ,andere berufliche Gymnasien“, „Fachgymnasium“, „Kolleg““.

„Realschule“: „Berufsaufbauschule“, „Wirtschaftsschule (Bayern)“ (leading to ,Mittlere Reife').

„Hauptschule“: "Berufseinstiegsschule (Niedersachsen)”.

"Non-tracked / other": "berufl. verbundene HS + Real", Mittelschule (regional differences HS/Real), Polytechnische Oberschule (Gesamtschule), Duale Oberschule (R-Pf, is "verbundene HS/Real"), „Berufsschule im dualen System“ (should not lead to a general school degree), „Berufsoberschule“ (depends on federal state if Abitur or only Fachabitur), "Berufskolleg”, „Fachschule“, „(Höhere) Berufsfachschule“, „Oberstufenzentrum“, „Schule des zweiten Bildungsweges“, „Höhere Handelsschule“ (the latter all leading to Fachabitur at last).

\section{f. Child information (spells, retrospectively): "SC3_spSchool"}

This dataset entails spell data provided by children with more detailed information on their school careers and detailed information on school tracks. This information was surveyed in waves $8,9 \& 10$. This information is not included in the NEPS-generated variable. This is retrospective information with a maximum of 8 years into the past. Hence, it is the least prioritized information we use. The dataset entails equivalent variables on school types as "SC3_pTarget". Hence, we used information on special types of schools as described in the previous step.

\section{g. Child biography data (spells): "SC3_Biography"}

This dataset entails spell data provided retrospectively by children in waves 8 and 9. It does, however, not entail information on school tracks. Instead, it provides additional 
information about missing values (“downgrade/dropout" vs. "left survey"). We used the main spells to identify the main activity during the respective key month. When main spells were unavailable, we used side spells accordingly.

\section{h. Further information from "Cohort Profile"}

This dataset entails meta data on the survey participants. The information allowed us to identify further participants who left the survey and therefore provided no information on school track.

\section{Merging all available school track information}

We started with the full NEPS sample including all 10 waves: 8,317 children and 78,760 observations. First, we deleted all children (20,980 person-years and 2,539 children) who did not participate in the first wave (mainly targeting the reinforcement sample). Next, we deleted all children who did not visit a Gymnasium in wave 1 according to the NEPS-generated variable $^{9}\left(5^{\text {th }}\right.$ grade; 34,070 person-years and 3,407 children). Our remaining sample consisted of 2,371 children and 23,710 person-years. We started with 23,710 missing person-years.

We prioritized the data sources on current school track in the following way:

$1 \quad$ Waves 1-10: Individual tracking

(Person-years updated: 795)

$2 \quad$ Waves 1-6: NEPS-generated variable

(Person-years updated: 12,228)

3 Waves 1-6: Parental information (spells)

(Person-years updated: 293)

$4 \quad$ Waves 7-10: Child information (cross-sectional)

(Person-years updated: 2,748)

5 Waves 1-10: Child information (spells, retrospectively)

(Person-years updated: 3,124)

$6 \quad$ Waves 1-10: Child biography data (spells)

(Person-years updated: 88 )

7 Waves 1-10: Further information from "Cohort Profile"

(Person-years updated: 2,133)

\footnotetext{
${ }^{9}$ Only for the first wave, the NEPS-generated track variable is entirely reliable and free from missing values. Therefore, we can use it to restrict our sample before constructing the augmented track variable.
} 
We did not overwrite any valid observations when combining the information. Individual tracking (1) had the highest priority because for individually tracked children, information from both parents and classmates $(2+3)$ is unavailable or unreliable. Parental information $(2+3)$ was added afterwards, because the generated variable is very reliable for the first six waves and parental spells were surveyed more immediately than the retrospective child information (5). Child cross-sectional information (4) was prioritized over child spells $(5,6)$ because answers given about the current school type should be more reliable than retrospective answers.

\section{Final steps}

The resulting sample consisted of 2,371 children in 10 waves. At this point, 2,301 out of 23,710 observations of the school track variable were still missing for unknown reasons (see Table A1, middle column).

Next, we replaced the remaining missing values by writing available information "backwards". For children with a missing value in the last available wave (10), we assumed that the child left the survey. Afterwards, we replaced missing values in waves 2-9 by the value in the following wave. We considered this the most conservative way of replacing the remaining missing values by making assumptions. Table A2 displays the distribution of the track variable before and after this step only for the subsample of the first six waves, which is the sample our main analyses are based on (columns two vs. three). Only 254 cases are being replaced through this step, the distribution of track statuses only changes marginally.

Finally, we added information on obtained upper secondary school degrees (Abitur). Making use of the dataset "SC3_Education", we identified the month when the highest degree was obtained. We matched this information with the child's interview month (see 2a.) to determine the first wave in which the track variable had to be changed. We recoded students who obtained an Abitur prior to January 2017 as having left the survey (because obtaining Abitur after less than 5.5 years in secondary school is highly unlikely). Table A1 displays the distribution of the reconstructed track variable before and after the augmentation routine was completed, together with an intermediate step to make transparent the implications of writing information backwards. Table A2 displays the same distribution, based only on the first six waves that are part of the main analyses in the paper. 
Table A1. Distribution of reconstructed track variable, only children who visited a Gymnasium in wave 1 (full sample; long-form dataset; $\mathrm{N}$ (individuals) = 2,371, N (personyears) $=23,710)$.

\begin{tabular}{lccc}
\hline & $\begin{array}{c}\text { Before: Original } \\
\text { NEPS-constructed } \\
\text { variable }\end{array}$ & $\begin{array}{c}\text { Intermediate: After } \\
\text { merging information }\end{array}$ & $\begin{array}{c}\text { Final: sample after } \\
\text { writing cases } \\
\text { backwards + adding } \\
\text { degree information }\end{array}$ \\
\hline Has Abitur & $0(0.00 \%)$ & $0(0.00 \%)$ & $1,004(4.23 \%)$ \\
Gymnasium & $16,593(69.98 \%)$ & $16,597(70.00 \%)$ & $17,164(72.39 \%)$ \\
Realschule & $7(0.03 \%)$ & $710(2.99 \%)$ & $749(3.16 \%)$ \\
Hauptschule & $0(0.00 \%)$ & $25(0.11 \%)$ & $28(0.12 \%)$ \\
non-tracked/other & $251(1.06 \%)$ & $629(2.65 \%)$ & $745(3.14 \%)$ \\
left school & $0(0.00 \%)$ & $1,325(5.59 \%)$ & $362(1.53 \%)$ \\
left survey & $0(0.00 \%)$ & $2,123(8.95 \%)$ & $3,658(15.43 \%)$ \\
\hline unknown & $6,859(28.93 \%)$ & $2,301(9.70 \%)$ & $0(0.00 \%)$ \\
\hline
\end{tabular}

Table A2. Distribution of reconstructed track variable until wave 6, only children who visited a Gymnasium in wave 1 (main analysis sample; long-form dataset; $\mathrm{N}$ (individuals) $=2,371, \mathrm{~N}$ (person-years) $=14,226)$.

\begin{tabular}{lccc}
\hline & $\begin{array}{c}\text { Before: Original } \\
\text { NEPS-constructed } \\
\text { variable }\end{array}$ & $\begin{array}{c}\text { Intermediate: After } \\
\text { merging information }\end{array}$ & $\begin{array}{c}\text { Final: sample after } \\
\text { writing cases } \\
\text { backwards }\end{array}$ \\
\hline Has Abitur & $0(0.00 \%)$ & $0(0.00 \%)$ & $0(0.00 \%)$ \\
Gymnasium & $12,095(85.02 \%)$ & $12,744(89.58 \%)$ & $12,815(90.08 \%)$ \\
Realschule & $7(0.05 \%)$ & $476(3.35 \%)$ & $510(3.58 \%)$ \\
Hauptschule & $0(0.00 \%)$ & $16(0.11 \%)$ & $18(0.13 \%)$ \\
non-tracked/other & $128(0.90 \%)$ & $312(2.19 \%)$ & $346(2.43 \%)$ \\
left school & $0(0.00 \%)$ & $1(0.01 \%)$ & $1(0.01 \%)$ \\
left survey & $0(0.00 \%)$ & $423(2.97 \%)$ & $536(3.77 \%)$ \\
\hline unknown & $1,996(14.03 \%)$ & $254(1.79 \%)$ & $0(0.00 \%)$ \\
\hline
\end{tabular}




\section{B. Correcting for the selection into Gymnasium}

If we are interested in the causal effect of academic preparedness on the risk of downgrading from Gymnasium among all students (not only those who attend the Gymnasium), we have to adjust for the selection into Gymnasium because conditioning on Gymnasium attendance introduces a collider bias for the association between academic preparedness on the risk of downgrading. This becomes clear when presenting the conceptual model in Figure 1 as a directed acyclic graph.

Figure B1. Directed acyclic graph of the conceptual model

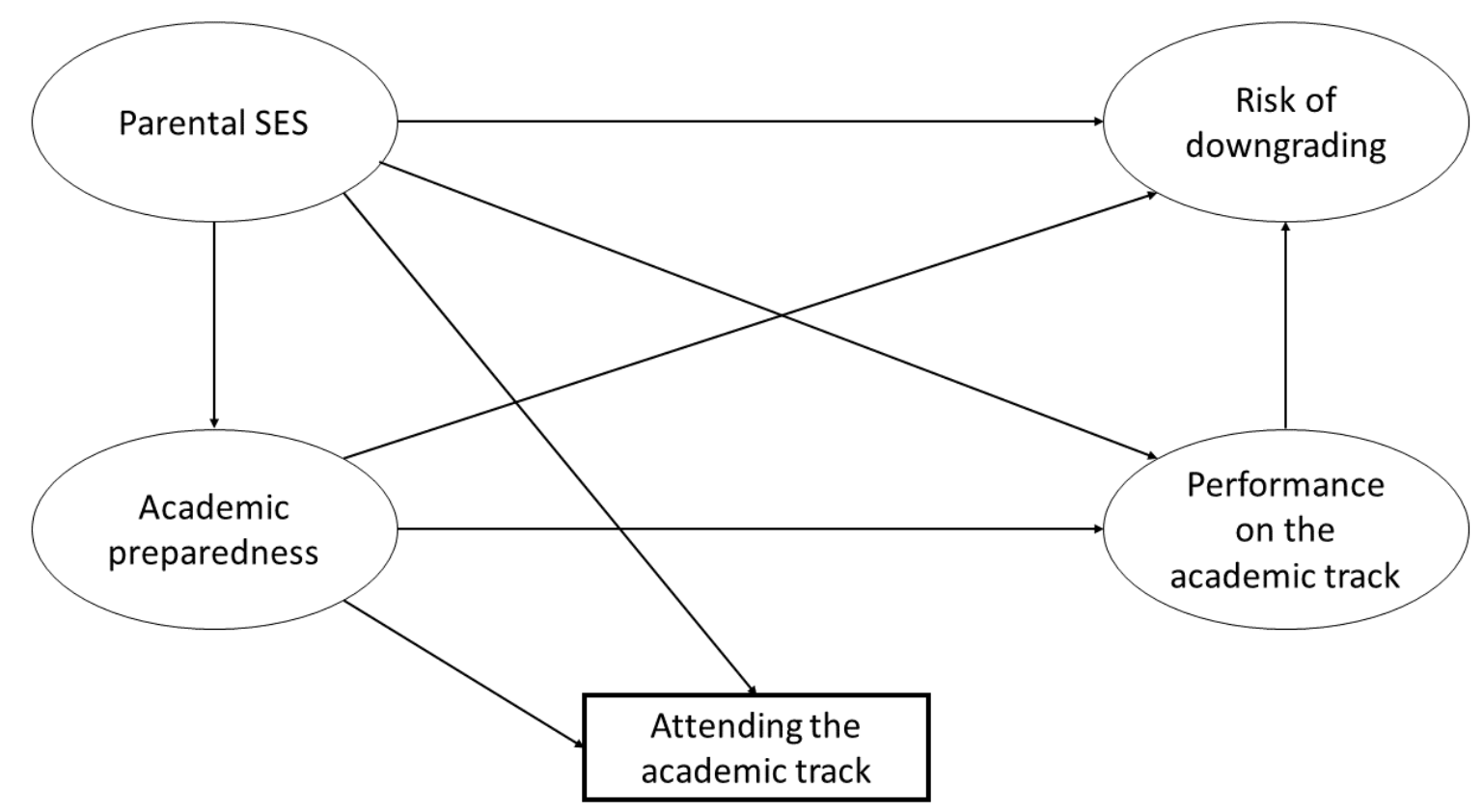

When analyzing the causal effect of academic preparedness on the risk of downgrading (academic preparedness $\rightarrow$ risk of downgrading), we have to restrict or analysis to those children who are attending Gymnasium (as indicated by the square around 'attending the academic track'). However, the attended track is collider - a descendant of both parental SES and academic preparedness (parental SES $\rightarrow$ attending the academic track $\leftarrow$ academic preparedness). Therefore, by restricting our analysis to those children that attend the academic track, we open the non-causal backdoor path academic preparedness $\rightarrow$ attending the academic track $\leftarrow$ parental SES $\rightarrow$ risk of downgrading.

We can correct for this selection bias by weighting students by the inverse of their probability to attend the academic track (Hernán \& Robins, 2020). We use a logistic regression model to estimate the probability to attend the Gymnasium using the same variables as in the survival 
analysis as predictors (competence score, parental education, control variables). Table B1 shows the results of this regression. 
Table B1. Logistic regression of attending Gymnasium on competence score, parental education and control variables

\begin{tabular}{lcc}
\hline & $\mathrm{b}$ & $\mathrm{SE}$ \\
\hline & & \\
Competence score & $1.474^{* * *}$ & $(0.053)$ \\
Parents have tertiary education & $0.874^{* * *}$ & $(0.097)$ \\
West Germany & 0.228 & $(0.131)$ \\
Girl & 0.079 & $(0.074)$ \\
Native & Reference & \\
1. Generation & $0.542^{* *}$ & $(0.204)$ \\
2. Generation & $0.530^{* * *}$ & $(0.098)$ \\
Both biological parents & Reference & \\
Single parents & $-0.401^{* *}$ & $(0.124)$ \\
Stepfamily & $-0.301^{*}$ & $(0.126)$ \\
Other constellation & $-0.399^{* *}$ & $(0.151)$ \\
Birthyear parents & -0.015 & $(0.009)$ \\
Age child & $0.081^{* * *}$ & $(0.007)$ \\
Constant & -8.522 & \\
\hline$N$ & 4803 & $(16.835)$ \\
\hline
\end{tabular}

Standard errors in parentheses

${ }^{*} p<0.05,{ }^{* *} p<0.01,{ }^{* * *} p<0.001$

When applying these weights to the sample of students in Gymnasium, we observe substantially worse GPA in Gymnasium (2.75 instead of 2.60 in the unweighted sample) and larger hazard of downgrading (5.4\% instead of $2.9 \%$ ). However, despite for this change in levels, we see a similar pattern regarding the hazard of downgrading, the catch-up mechanisms, and the carryon mechanism. 
Figure B2. Predicted hazard of downgrading by competence score and parental education when adjusting for selection into Gymnasium attendance

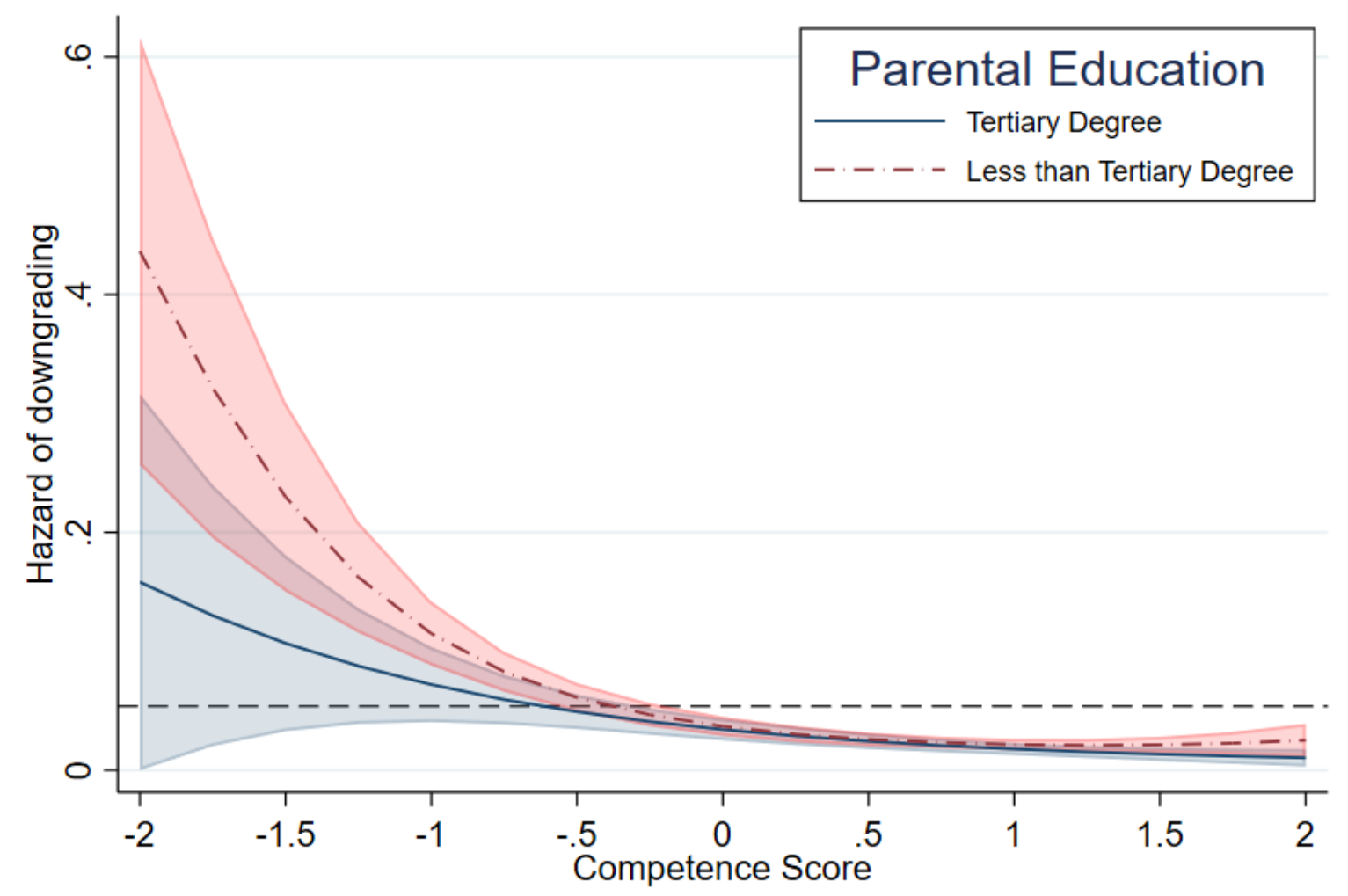


Figure B3. Predicted GPA in Gymnasium by competence score and parental education when adjusting for selection into Gymnasium attendance

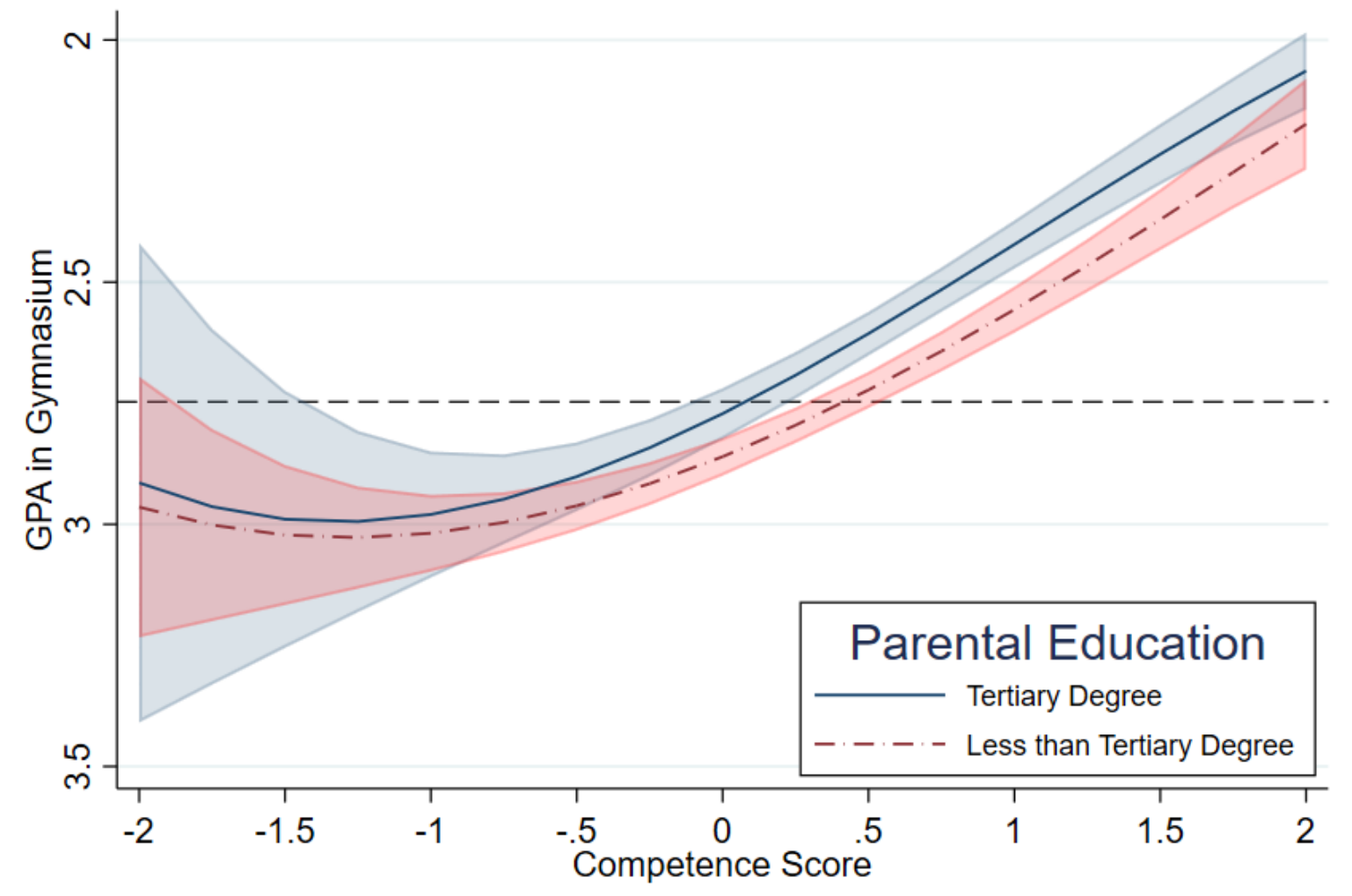


Figure B4. Hazard of downgrading by GPA in Gymnasium and parental education when adjusting for selection into Gymnasium attendance

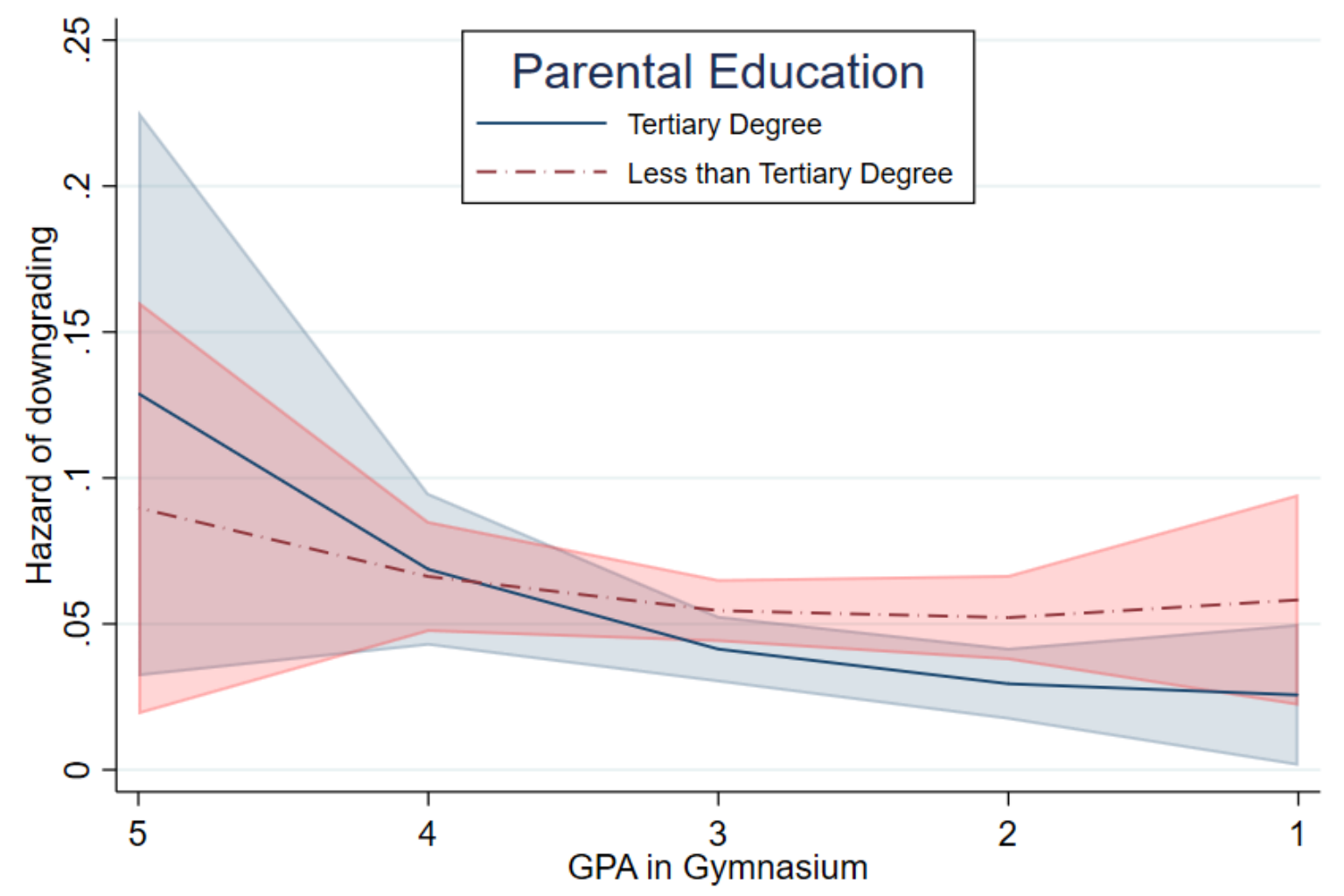




\section{Regression coefficients of main models}

Table C1. Regression coefficients of the competing risk survival analysis of survival state on competence score and parental education

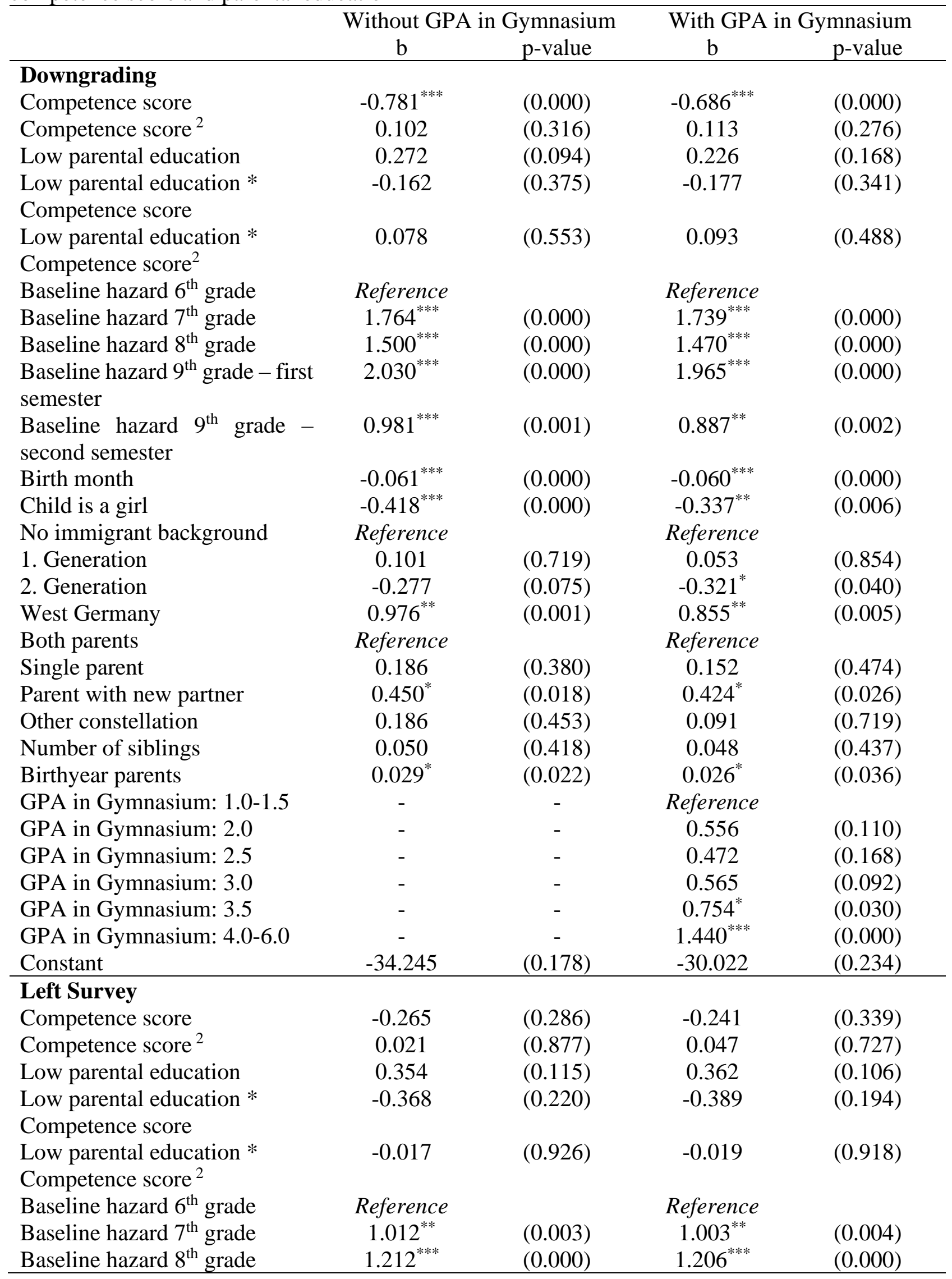




\begin{tabular}{|c|c|c|c|c|}
\hline $\begin{array}{l}\text { Baseline hazard } 9^{\text {th }} \text { grade }- \text { first } \\
\text { semester }\end{array}$ & $2.368^{* * *}$ & $(0.000)$ & $2.359^{* * *}$ & $(0.000)$ \\
\hline $\begin{array}{l}\text { Baseline hazard } 9^{\text {th }} \text { grade - } \\
\text { second semester }\end{array}$ & $1.043^{* *}$ & $(0.003)$ & $1.030^{* *}$ & $(0.004)$ \\
\hline Birth month & -0.018 & $(0.234)$ & -0.018 & $(0.241)$ \\
\hline Child is a girl & -0.246 & $(0.099)$ & -0.240 & $(0.112)$ \\
\hline No immigrant background & Reference & & Reference & \\
\hline 1. Generation & 0.556 & $(0.105)$ & 0.567 & $(0.099)$ \\
\hline 2. Generation & 0.288 & $(0.118)$ & 0.295 & $(0.111)$ \\
\hline West Germany & 0.132 & $(0.638)$ & 0.126 & $(0.658)$ \\
\hline Both parents & Reference & & Reference & \\
\hline Single parent & 0.425 & $(0.088)$ & 0.416 & $(0.098)$ \\
\hline Parent with new partner & $0.507^{*}$ & $(0.043)$ & $0.501^{*}$ & $(0.046)$ \\
\hline Other constellation & 0.009 & $(0.981)$ & 0.005 & $(0.989)$ \\
\hline Number of siblings & -0.060 & $(0.532)$ & -0.060 & $(0.530)$ \\
\hline Birthyear parents & 0.023 & $(0.201)$ & 0.022 & $(0.205)$ \\
\hline GPA in Gymnasium: $1.0-1.5$ & - & - & Reference & \\
\hline GPA in Gymnasium: 2.0 & - & - & 0.610 & $(0.283)$ \\
\hline GPA in Gymnasium: 2.5 & - & - & 0.715 & $(0.171)$ \\
\hline GPA in Gymnasium: 3.0 & - & - & 0.734 & $(0.205)$ \\
\hline GPA in Gymnasium: 3.5 & - & - & 0.533 & $(0.355)$ \\
\hline GPA in Gymnasium: 4.0-6.0 & - & - & 0.376 & $(0.553)$ \\
\hline Constant & -40.978 & $(0.245)$ & -41.390 & $(0.242)$ \\
\hline Individuals & 2,371 & & 2,371 & \\
\hline Person-years & 10,938 & & 10,938 & \\
\hline
\end{tabular}


Table C2. Regression coefficients of the linear mixed models of GPA in Gymnasium on competence score and parental education

\begin{tabular}{|c|c|c|}
\hline & $\mathrm{b}$ & p-value \\
\hline Competence score & $-0.301^{* * * *}$ & $(0.000)$ \\
\hline Competence score $^{2}$ & -0.070 & $(0.062)$ \\
\hline Competence score ${ }^{3}$ & 0.022 & $(0.100)$ \\
\hline Low parental education & $0.089^{*}$ & $(0.013)$ \\
\hline Low parental education * & 0.057 & $(0.233)$ \\
\hline Competence score & & \\
\hline Low parental education * & -0.003 & $(0.952)$ \\
\hline Competence score $^{2}$ & & \\
\hline $\begin{array}{l}\text { Low parental education * } \\
\text { Competence score } \\
3\end{array}$ & -0.010 & $(0.550)$ \\
\hline Birth month & -0.001 & $(0.650)$ \\
\hline Child is a girl & $-0.167^{* * *}$ & $(0.000)$ \\
\hline No immigrant background & Reference & \\
\hline 1. Generation & 0.087 & $(0.204)$ \\
\hline 2. Generation & $0.092^{* *}$ & $(0.003)$ \\
\hline West Germany & $0.244^{* * *}$ & $(0.000)$ \\
\hline Both parents & Reference & \\
\hline Single parent & $0.160^{* * *}$ & $(0.000)$ \\
\hline Parent with new partner & 0.081 & $(0.065)$ \\
\hline Other constellation & $0.188^{* *}$ & $(0.001)$ \\
\hline Number of siblings & 0.006 & $(0.642)$ \\
\hline Birthyear parents & 0.004 & $(0.151)$ \\
\hline Constant & -3.988 & $(0.423)$ \\
\hline Individuals & 2,371 & \\
\hline Person-years & 10,938 & \\
\hline
\end{tabular}


Table C3. Regression coefficients of the competing risk survival analysis of survival state on GPA in Gymnasium and parental education

\begin{tabular}{|c|c|c|}
\hline & $\mathrm{b}$ & p-value \\
\hline \multicolumn{3}{|l|}{ Downgrading } \\
\hline Competence score & $-0.806^{* * *}$ & $(0.000)$ \\
\hline Competence score $^{2}$ & $0.181^{* *}$ & $(0.004)$ \\
\hline Baseline hazard $6^{\text {th }}$ grade & Reference & \\
\hline Baseline hazard $7^{\text {th }}$ grade & $1.734^{* * * *}$ & $(0.000)$ \\
\hline Baseline hazard $8^{\text {th }}$ grade & $1.467^{* * *}$ & $(0.000)$ \\
\hline $\begin{array}{l}\text { Baseline hazard } 9^{\text {th }} \text { grade }- \text { first } \\
\text { semester }\end{array}$ & $1.961^{* * * *}$ & $(0.000)$ \\
\hline $\begin{array}{l}\text { Baseline hazard } 9^{\text {th }} \text { grade - } \\
\text { second semester }\end{array}$ & $0.877^{* *}$ & $(0.003)$ \\
\hline Birth month & $-0.060^{* * * *}$ & $(0.000)$ \\
\hline Child is a girl & $-0.326^{* *}$ & $(0.008)$ \\
\hline No immigrant background & Reference & \\
\hline 1. Generation & 0.043 & $(0.879)$ \\
\hline 2. Generation & -0.302 & $(0.052)$ \\
\hline West Germany & $0.893^{* *}$ & $(0.003)$ \\
\hline Both parents & Reference & \\
\hline Single parent & 0.159 & $(0.455)$ \\
\hline Parent with new partner & $0.428^{*}$ & $(0.025)$ \\
\hline Other constellation & 0.052 & $(0.837)$ \\
\hline Number of siblings & 0.042 & $(0.500)$ \\
\hline Birthyear parents & $0.026^{*}$ & $(0.036)$ \\
\hline GPA in Gymnasium: $1.0-1.5$ & Reference & \\
\hline GPA in Gymnasium: 2.0 & 0.311 & $(0.582)$ \\
\hline GPA in Gymnasium: 2.5 & 0.390 & $(0.482)$ \\
\hline GPA in Gymnasium: 3.0 & 0.481 & $(0.392)$ \\
\hline GPA in Gymnasium: 3.5 & 1.082 & $(0.053)$ \\
\hline GPA in Gymnasium: 4.0-6.0 & $1.742^{* *}$ & $(0.002)$ \\
\hline Low parental education & 0.288 & $(0.647)$ \\
\hline Low parental education * & 0.397 & $(0.595)$ \\
\hline \multicolumn{3}{|l|}{ GPA in Gymnasium: 2.0} \\
\hline Low parental education * & 0.137 & $(0.852)$ \\
\hline \multicolumn{3}{|l|}{ GPA in Gymnasium: 2.5} \\
\hline Low parental education * & 0.126 & $(0.860)$ \\
\hline \multicolumn{3}{|l|}{ GPA in Gymnasium: 3.0} \\
\hline Low parental education * & -0.484 & $(0.510)$ \\
\hline \multicolumn{3}{|l|}{ GPA in Gymnasium: 3.5} \\
\hline Low parental education * & -0.426 & $(0.555)$ \\
\hline \multicolumn{3}{|l|}{ GPA in Gymnasium: 4.0-6.0 } \\
\hline Constant & -30.053 & $(0.234)$ \\
\hline \multicolumn{3}{|l|}{ Left survey } \\
\hline Competence score & $-0.503^{* * *}$ & $(0.000)$ \\
\hline Competence score $^{2}$ & 0.078 & $(0.361)$ \\
\hline Baseline hazard $6^{\text {th }}$ grade & Reference & \\
\hline Baseline hazard $7^{\text {th }}$ grade & $1.003^{* *}$ & $(0.004)$ \\
\hline Baseline hazard $8^{\text {th }}$ grade & $1.204^{* * * *}$ & $(0.000)$ \\
\hline $\begin{array}{l}\text { Baseline hazard } 9^{\text {th }} \text { grade }- \text { first } \\
\text { semester }\end{array}$ & $2.356^{* * *}$ & $(0.000)$ \\
\hline
\end{tabular}




\begin{tabular}{|c|c|c|}
\hline $\begin{array}{l}\text { Baseline hazard } 9^{\text {th }} \text { grade - } \\
\text { second semester }\end{array}$ & $1.023^{* *}$ & $(0.004)$ \\
\hline Birth month & -0.018 & $(0.230)$ \\
\hline Child is a girl & -0.230 & $(0.129)$ \\
\hline No immigrant background & Reference & \\
\hline 1. Generation & 0.560 & $(0.103)$ \\
\hline 2. Generation & 0.322 & $(0.080)$ \\
\hline West Germany & 0.147 & $(0.606)$ \\
\hline Both parents & Reference & \\
\hline Single parent & 0.413 & $(0.100)$ \\
\hline Parent with new partner & $0.503^{*}$ & $(0.045)$ \\
\hline Other constellation & -0.047 & $(0.902)$ \\
\hline Number of siblings & -0.063 & $(0.513)$ \\
\hline Birthyear parents & 0.022 & $(0.211)$ \\
\hline GPA in Gymnasium: $1.0-1.5$ & Reference & \\
\hline GPA in Gymnasium: 2.0 & 1.394 & $(0.989)$ \\
\hline GPA in Gymnasium: 2.5 & 1.509 & $(0.988)$ \\
\hline GPA in Gymnasium: 3.0 & 1.551 & $(0.987)$ \\
\hline GPA in Gymnasium: 3.5 & 1.589 & $(0.987)$ \\
\hline GPA in Gymnasium: 4.0-6.0 & 1.279 & $(0.994)$ \\
\hline Low parental education & 1.131 & $(0.991)$ \\
\hline Low parental education * & -0.796 & $(0.994)$ \\
\hline \multicolumn{3}{|l|}{ GPA in Gymnasium: 2.0} \\
\hline Low parental education * & -0.826 & $(0.993)$ \\
\hline \multicolumn{3}{|l|}{ GPA in Gymnasium: 2.5} \\
\hline Low parental education * & -0.868 & $(0.993)$ \\
\hline \multicolumn{3}{|l|}{ GPA in Gymnasium: 3.0} \\
\hline Low parental education * & -1.225 & $(0.990)$ \\
\hline \multicolumn{3}{|l|}{ GPA in Gymnasium: 3.5} \\
\hline Low parental education $*$ & -1.156 & $(0.995)$ \\
\hline \multicolumn{3}{|l|}{ GPA in Gymnasium: 4.0-6.0 } \\
\hline Constant & -41.313 & $(0.691)$ \\
\hline Individuals & 2,371 & \\
\hline Person-years & 10,938 & \\
\hline
\end{tabular}

Reference survival state: Staying in Gymnasium. Significance Levels: *** p-value $<0.001$; ** p-value $<0.01, *$ p-value $<0.05$. 


\section{Predicted probabilities}

Table D1. Predicted hazard of downgrading by competence score and parental education

\begin{tabular}{lllll}
\hline $\begin{array}{l}\text { Competence } \\
\text { Score }\end{array}$ & $\begin{array}{l}\text { High } \\
\text { education }\end{array}$ & Low education & $\begin{array}{l}\text { Difference by } \\
\text { education }\end{array}$ & $\begin{array}{l}\text { p-value of } \\
\text { difference }\end{array}$ \\
\hline-1.5 & 0.107 & 0.179 & 0.072 & 0.141 \\
-1.0 & 0.068 & 0.104 & 0.036 & 0.069 \\
-0.5 & 0.045 & 0.062 & 0.017 & 0.044 \\
0.0 & 0.030 & 0.039 & 0.008 & 0.099 \\
0.5 & 0.021 & 0.026 & 0.005 & 0.213 \\
1.0 & 0.016 & 0.019 & 0.003 & 0.323 \\
1.5 & 0.012 & 0.015 & 0.003 & 0.449 \\
2.0 & 0.010 & 0.013 & 0.003 & 0.547 \\
2.5 & 0.009 & 0.012 & 0.004 & 0.600 \\
\hline
\end{tabular}

Table D2. Mediation of the difference in the hazard of downgrading by parental education through GPA in Gymnasium, over competence scores.

\begin{tabular}{llllll}
\hline $\begin{array}{l}\text { Competence } \\
\text { Score }\end{array}$ & $\begin{array}{l}\text { Not via } \\
\text { performance }\end{array}$ & p-value & $\begin{array}{l}\text { Via } \\
\text { performance }\end{array}$ & p-value & $\begin{array}{l}\text { Percent via } \\
\text { performance }\end{array}$ \\
\hline-1.5 & 0.0645 & 0.1469 & 0.0078 & 0.4185 & 10.8 \\
-1.0 & 0.0305 & 0.0866 & 0.0052 & 0.1910 & 14.5 \\
-0.5 & 0.0140 & 0.0749 & 0.0031 & 0.0416 & 18.4 \\
0.0 & 0.0066 & 0.1803 & 0.0019 & 0.0064 & 22.7 \\
0.5 & 0.0035 & 0.3514 & 0.0012 & 0.0081 & 25.5 \\
1.0 & 0.0025 & 0.4577 & 0.0007 & 0.0796 & 21.5 \\
1.5 & 0.0026 & 0.5270 & 0.0002 & 0.7118 & 7.4 \\
2.0 & 0.0034 & 0.5705 & -0.0004 & 0.7437 & -12.8 \\
2.5 & 0.0050 & 0.5897 & -0.0013 & 0.6184 & -34.3 \\
\hline
\end{tabular}

Note: The total difference by education and their $\mathrm{p}$-values are reported in the last two columns of Table D1.

Table D3. Predicted GPA in Gymnasium by competence score and parental education

\begin{tabular}{lllll}
\hline $\begin{array}{l}\text { Competence } \\
\text { Score }\end{array}$ & $\begin{array}{l}\text { High } \\
\text { education }\end{array}$ & Low education & $\begin{array}{l}\text { Difference } \\
\text { by } \\
\text { education }\end{array}$ & $\begin{array}{l}\text { p-value of } \\
\text { difference }\end{array}$ \\
\hline-1.5 & 2.967 & 2.999 & 0.032 & 0.849 \\
-1.0 & 2.957 & 2.996 & 0.040 & 0.641 \\
-0.5 & 2.878 & 2.940 & 0.061 & 0.201 \\
0.0 & 2.748 & 2.838 & 0.089 & 0.013 \\
0.5 & 2.583 & 2.699 & 0.116 & 0.000 \\
1.0 & 2.399 & 2.532 & 0.133 & 0.000 \\
1.5 & 2.213 & 2.347 & 0.134 & 0.003 \\
2.0 & 2.041 & 2.151 & 0.110 & 0.081 \\
2.5 & 1.900 & 1.953 & 0.053 & 0.629 \\
\hline
\end{tabular}


Table D4. Predicted hazard of downgrading by GPA in Gymnasium and parental education

\begin{tabular}{lllll}
\hline $\begin{array}{l}\text { Competence } \\
\text { Score }\end{array}$ & $\begin{array}{l}\text { High } \\
\text { education }\end{array}$ & Low education & $\begin{array}{l}\text { Difference } \\
\text { by } \\
\text { education }\end{array}$ & $\begin{array}{l}\text { p-value of } \\
\text { difference }\end{array}$ \\
\hline $1.0-1.5$ & 0.014 & 0.018 & 0.004 & 0.662 \\
2.0 & 0.018 & 0.034 & 0.016 & 0.079 \\
2.5 & 0.019 & 0.028 & 0.009 & 0.211 \\
3.0 & 0.021 & 0.031 & 0.010 & 0.179 \\
3.5 & 0.037 & 0.031 & -0.006 & 0.578 \\
$4.0-6.0$ & 0.067 & 0.059 & -0.007 & 0.715 \\
\hline
\end{tabular}




\section{E. Alternative negative experiences considered in the Ad-hoc analysis}

Table E1. Measurement of alternative negative events that may trigger downgrading

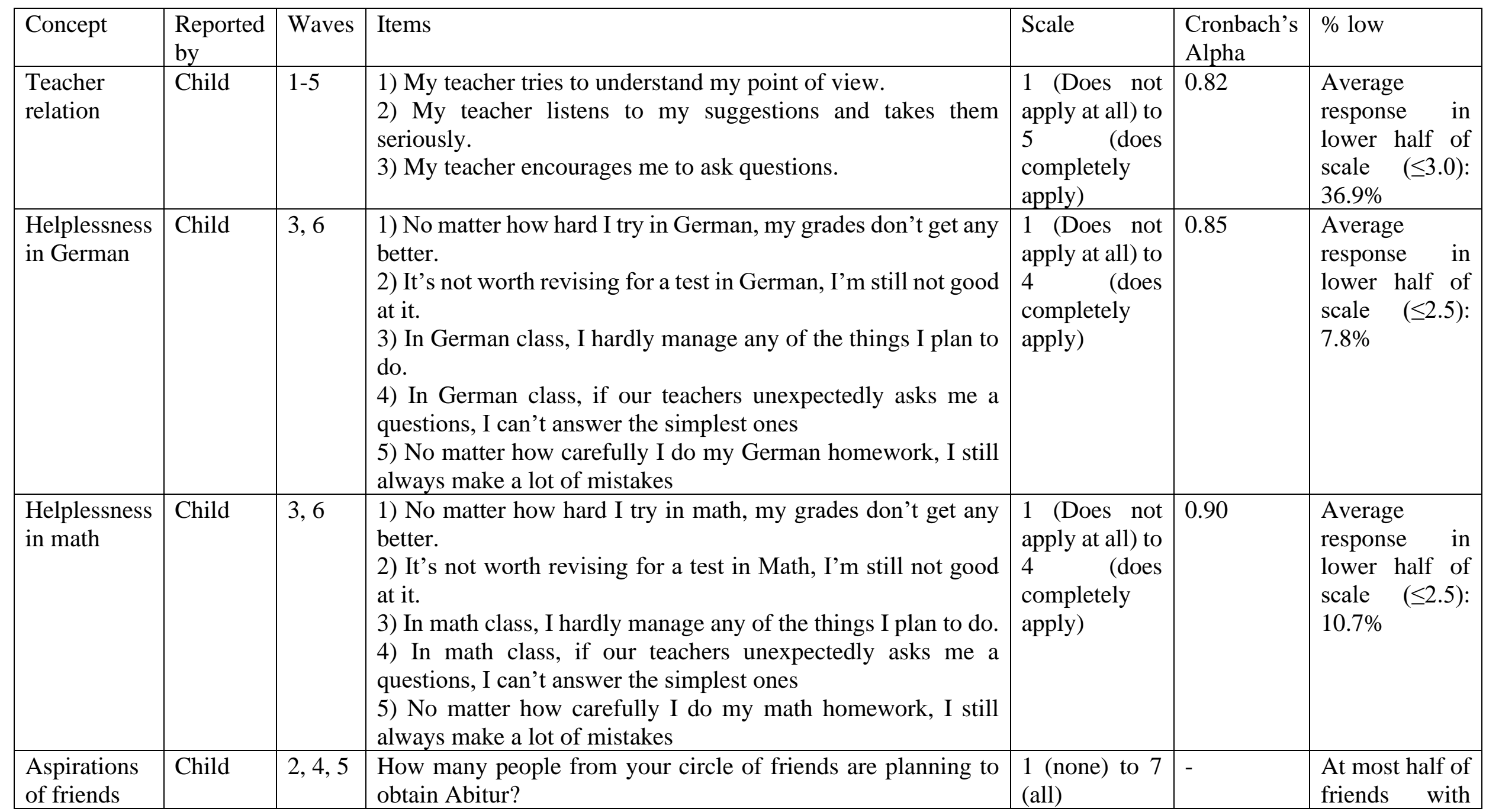




\begin{tabular}{|c|c|c|c|c|c|c|}
\hline & & & & & & $\begin{array}{l}\text { Aspirations for } \\
\text { Abitur } \quad(\leq 4) \text { : } \\
24.8 \%\end{array}$ \\
\hline $\begin{array}{l}\text { Self-concept } \\
\text { reading }\end{array}$ & Child & $\begin{array}{l}1,3,4, \\
6\end{array}$ & $\begin{array}{l}\text { 1) I sometimes have trouble understanding a text really well. } \\
\text { 2) I can understand texts very well and quickly. } \\
\text { 3) I have to read many things several times before I fully } \\
\text { understand them }\end{array}$ & $\begin{array}{l}1 \text { (completely } \\
\text { disagree) to } 4 \\
\text { (completely } \\
\text { agree) }\end{array}$ & 0.72 & $\begin{array}{l}\text { Average } \\
\text { response in } \\
\text { lower half of } \\
\text { scale }(\leq 2.5) \text { : } \\
13.5 \%\end{array}$ \\
\hline $\begin{array}{l}\text { Self-concept } \\
\text { school }\end{array}$ & Child & 1,5 & $\begin{array}{l}\text { 1) I learn fast in most of the school subjects. } \\
\text { 2) In most school subjects, I perform well in written class tests. } \\
\text { 3) I perform well in most school subjects. }\end{array}$ & $\begin{array}{l}1 \text { (Does not } \\
\text { apply at all) to } \\
4 \quad \text { (does } \\
\text { completely } \\
\text { apply) }\end{array}$ & 0.84 & $\begin{array}{l}\text { Average } \\
\text { response in } \\
\text { lower half of } \\
\text { scale }(\leq 2.5) \text { : } \\
11.8 \%\end{array}$ \\
\hline $\begin{array}{l}\text { Subjective } \\
\text { probability } \\
\text { of success }\end{array}$ & Child & $2,4,6$ & How likely to you think it is that you could obtain Abitur? & $\begin{array}{l}1 \text { (very } \\
\text { unlikely) to } 5 \\
\text { (very likely) }\end{array}$ & - & $\begin{array}{l}\text { About } 50 \% \\
\text { probability of } \\
\text { success or less } \\
(\leq 3): 24.6 \%\end{array}$ \\
\hline $\begin{array}{l}\text { Social } \\
\text { integration } \\
\text { in class }\end{array}$ & Parents & $2,3,4$ & $\begin{array}{l}\text { 1) The child has become well-integrated in class. } \\
\text { 2) The child is friends with many of the children in class. } \\
\text { 3) The child has made new friends in class. }\end{array}$ & $\begin{array}{l}1 \text { (Does not } \\
\text { apply at all) to } \\
4 \quad \text { (does } \\
\text { completely } \\
\text { apply) }\end{array}$ & 0.64 & $\begin{array}{l}\text { Average } \\
\text { response in } \\
\text { lower half of } \\
\text { scale }(\leq 2.5) \text { : } \\
5.3 \%\end{array}$ \\
\hline
\end{tabular}


Table E2. Mediation of the parental education gap in downgrading hazard through GPA and through GPA and other negative school experiences, over children's competence scores.

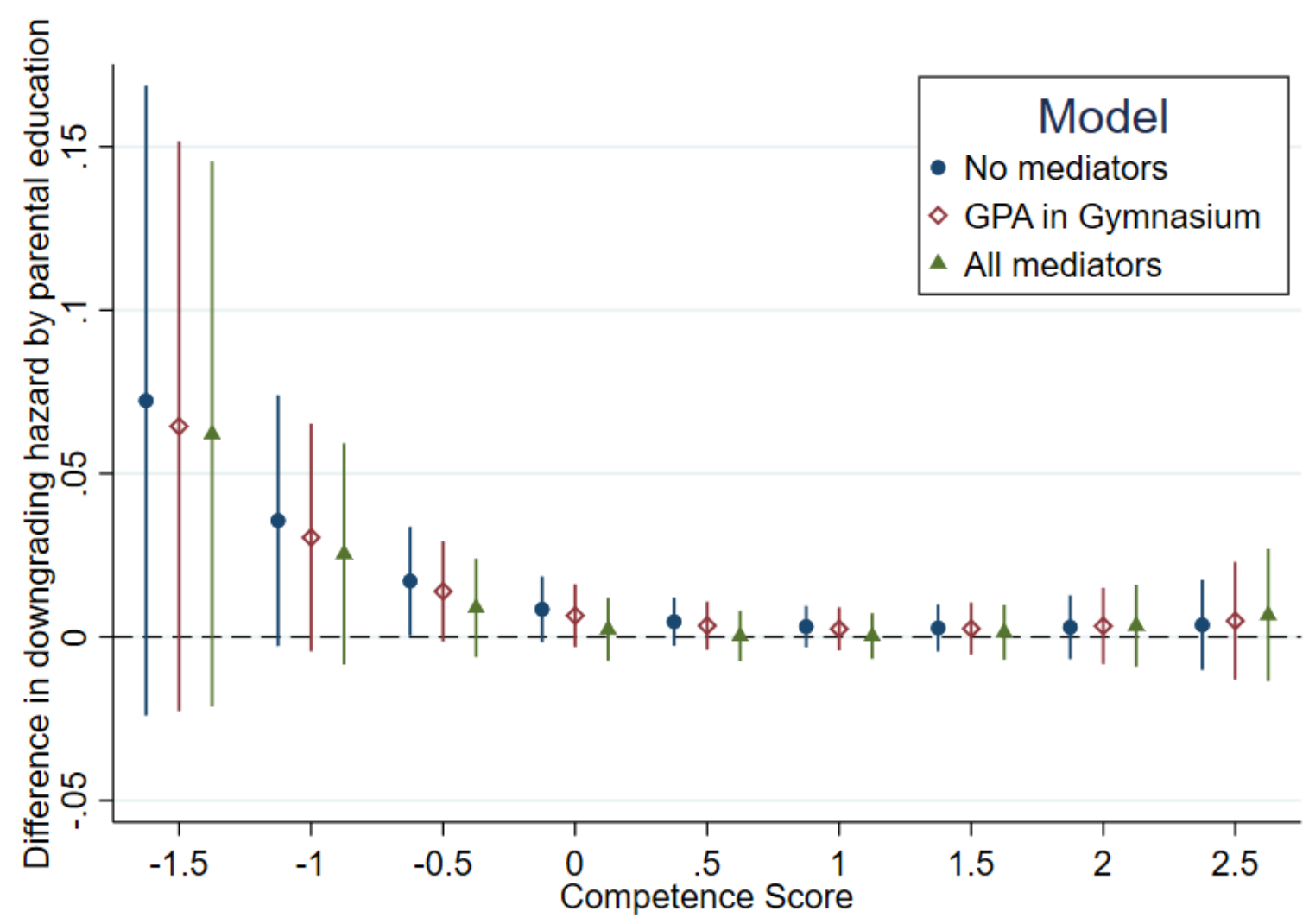


Table E3. Expected probability of negative school experiences by academic preparedness and parental education
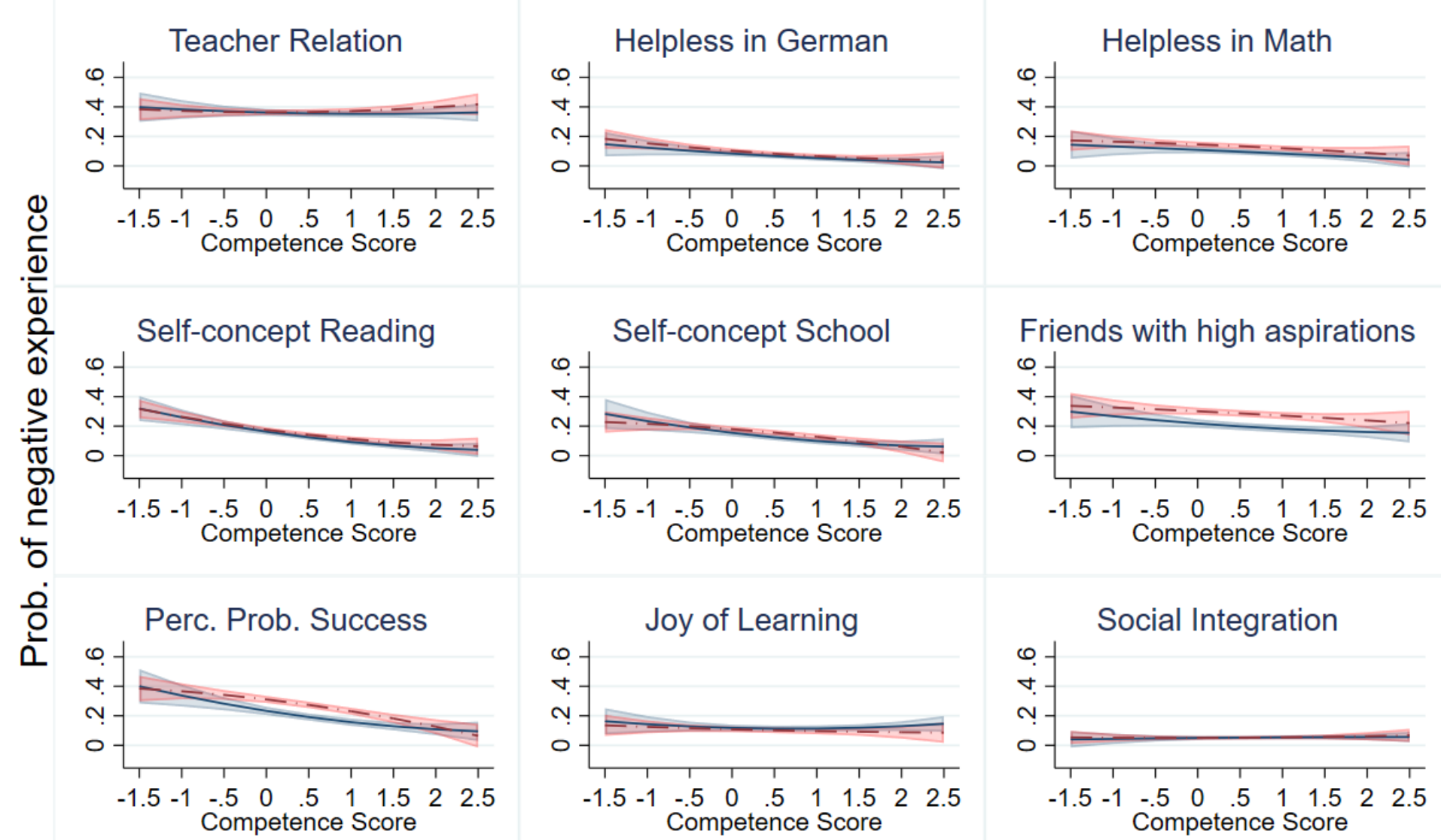

Friends with high aspirations
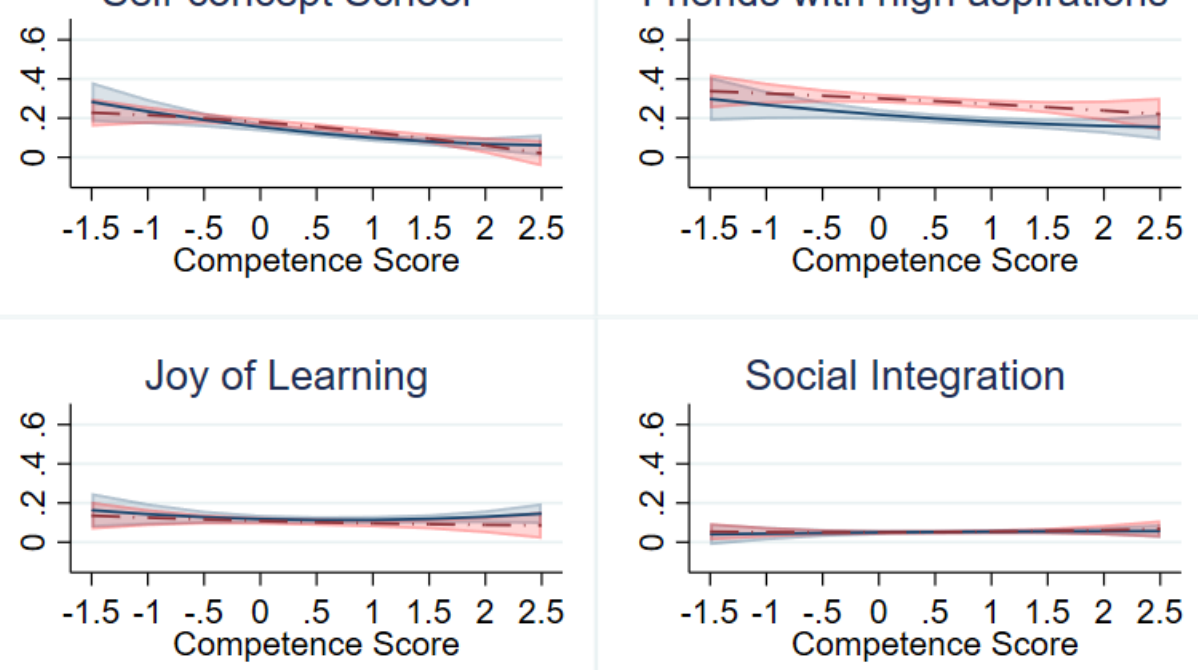

\section{Parental Education}

\section{Tertiary Degree $\quad-\quad \cdot-\cdot-$ Less than Tertiary Degree}


Table E4. Predicted hazard of downgrading by negative school experiences and parental education
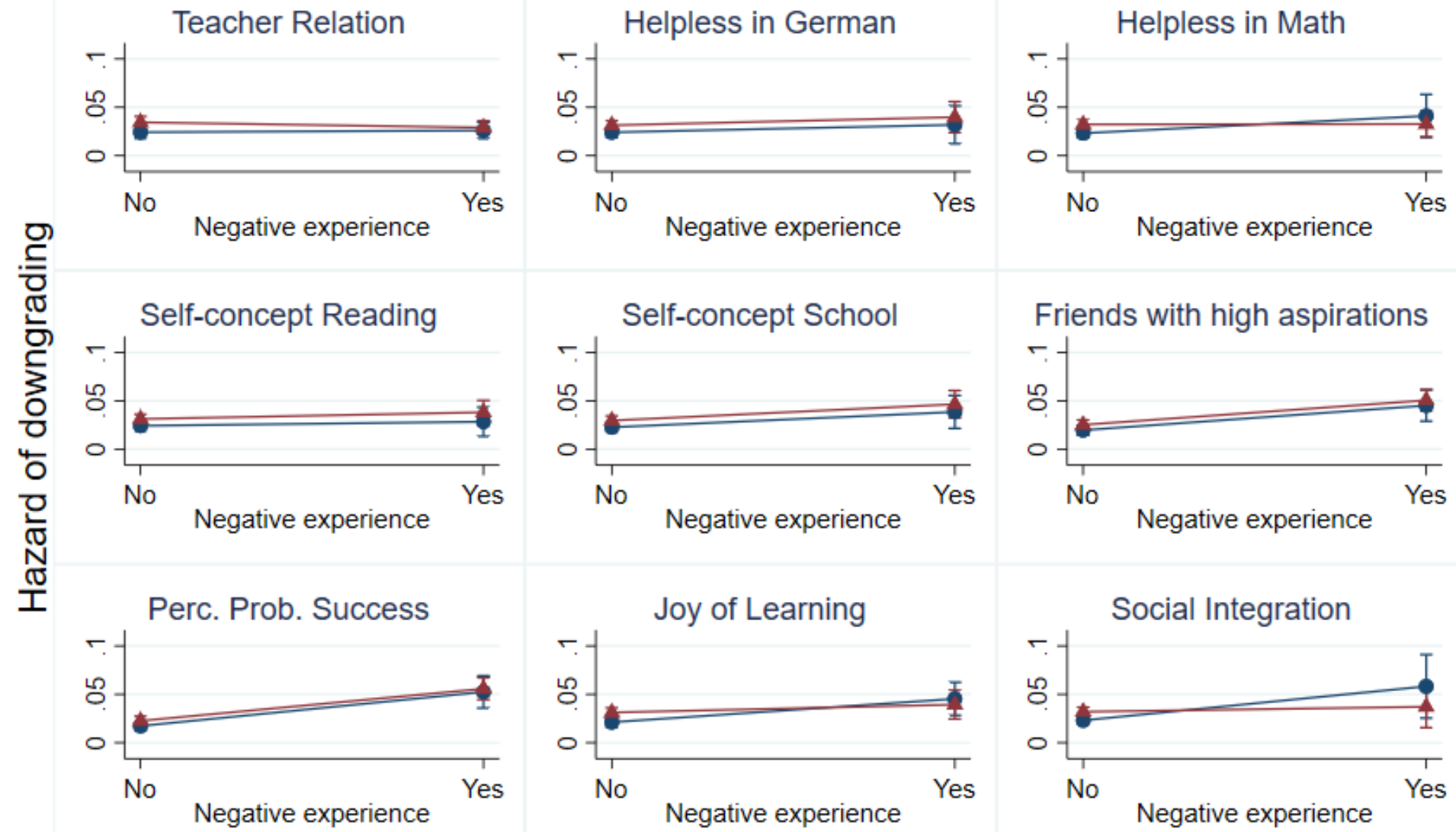

\section{Parental Education}

\section{Tertiary Degree $\quad \longrightarrow$ Less than Tertiary Degree}




\section{F. Robustness checks to operationalizations}

\section{F.1 GPA in primary school as measure of academic preparedness}

Figure F1. Predicted hazard of downgrading in primary school and parental education

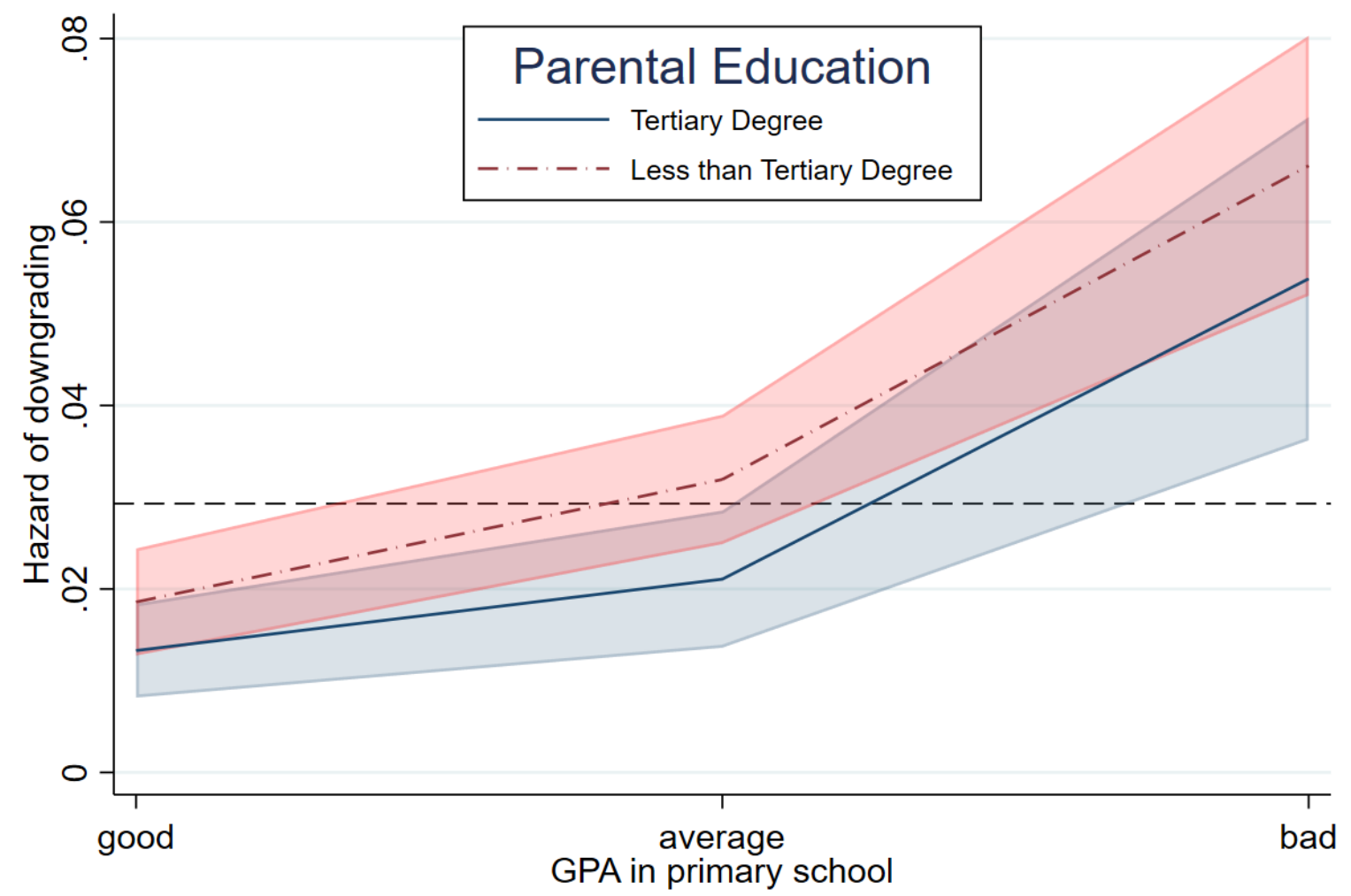

Note: Children with a GPA of 1.0 or 1.5 in primary school are coded as "good" $(39.5 \%)$, children with a GPA of 2.0 are coded as "average" (41.1\%), and children with a GPA of 2.5 or worse are coded as "bad" (19.4\%). 
Figure F2. Mediation of the parental education gap in downgrading hazard through GPA in Gymnasium, over children's primary school GPA.

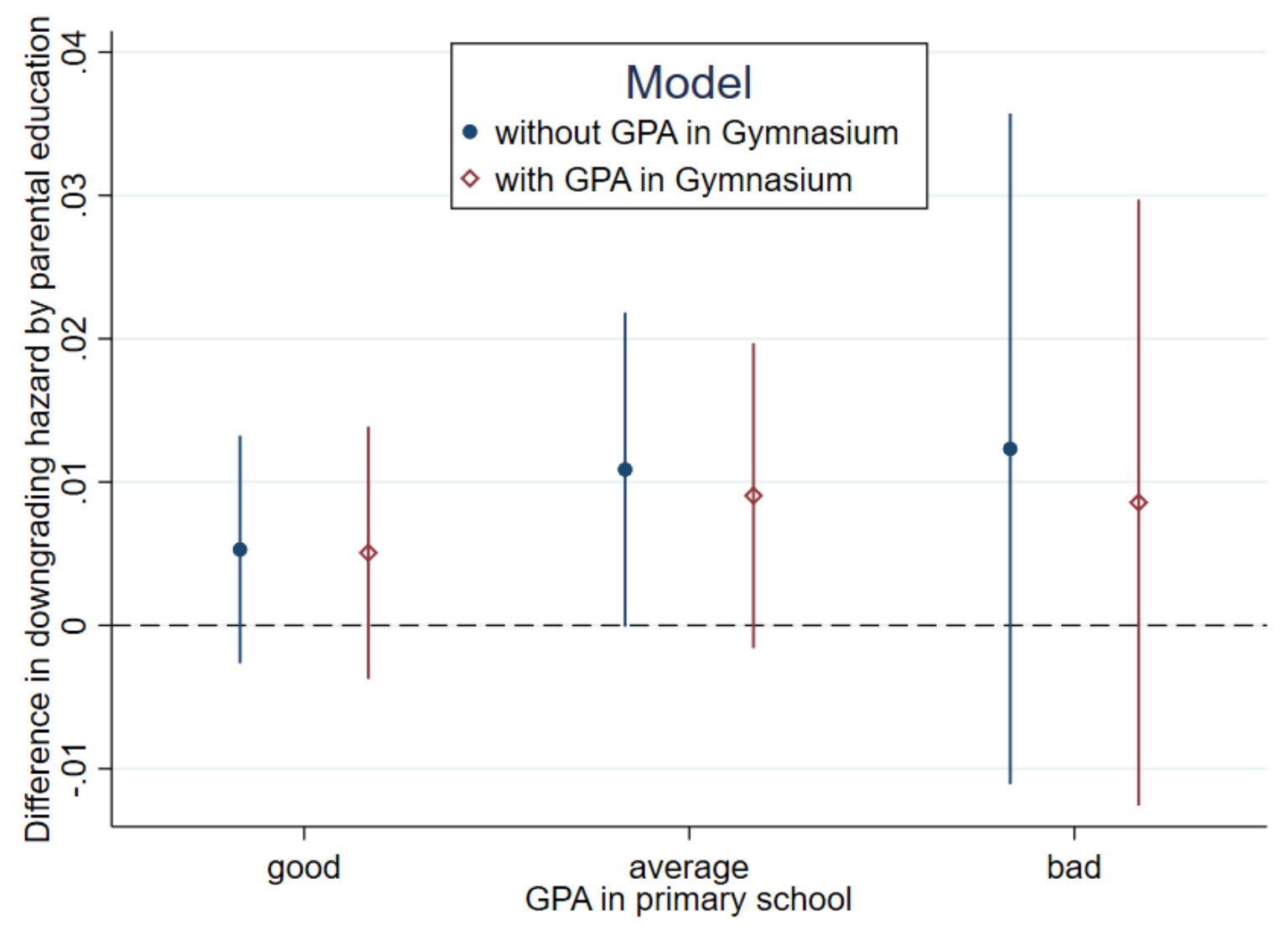

Note: Children with a GPA of 1.0 or 1.5 in primary school are coded as "good" $(39.5 \%)$, children with a GPA of 2.0 are coded as "average" (41.1\%), and children with a GPA of 2.5 or worse are coded as "bad" (19.4\%). 
Figure F3. Predicted GPA in Gymnasium by GPA in primary school and parental education

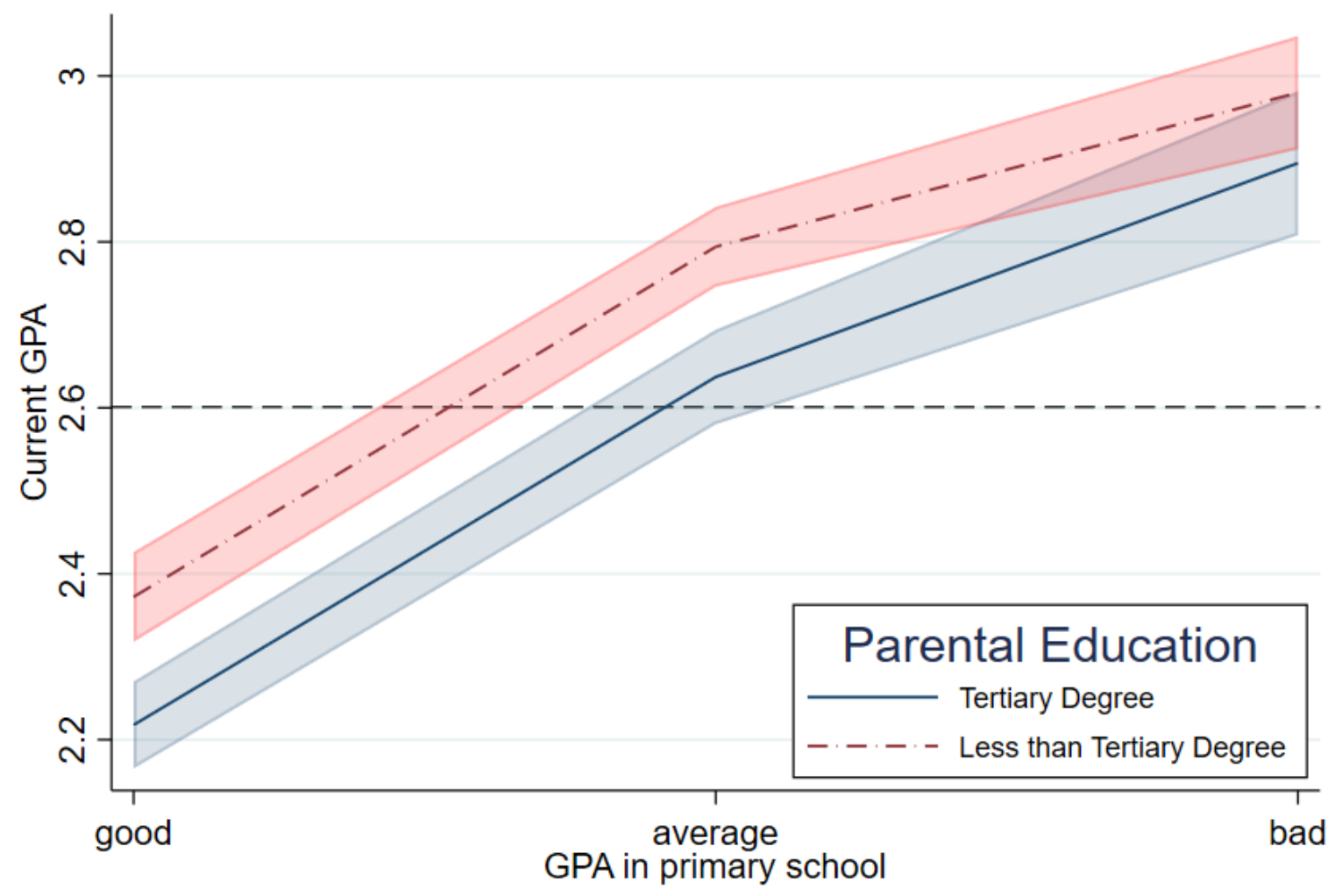

Note: Children with a GPA of 1.0 or 1.5 in primary school are coded as "good" $(39.5 \%)$, children with a GPA of 2.0 are coded as "average" (41.1\%), and children with a GPA of 2.5 or worse are coded as "bad" (19.4\%). 
F.2 Teacher's track recommendation as measure of academic preparedness

Figure F4. Hazard of downgrading by teacher's track recommendation and parental education

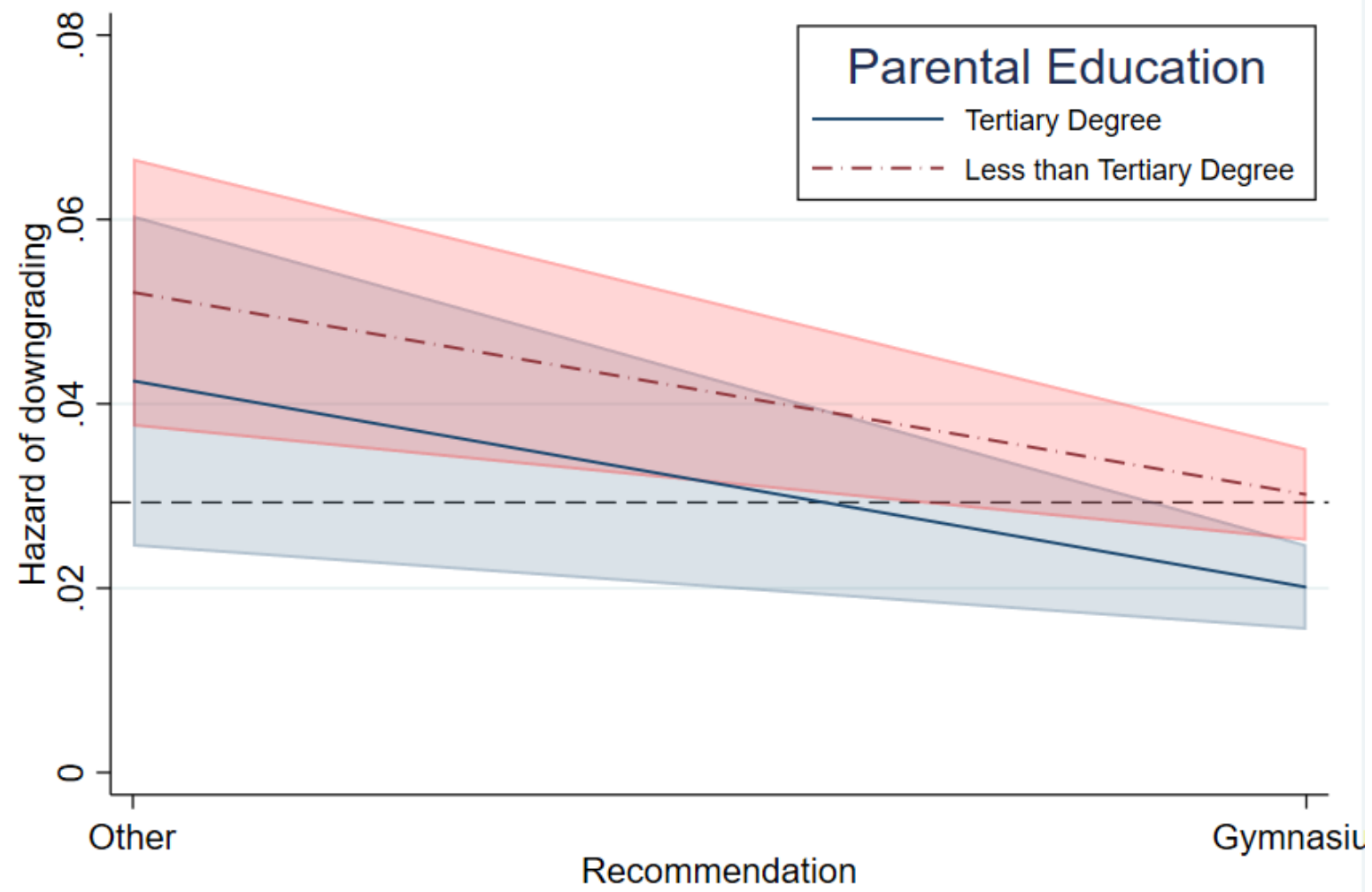




\section{F.3 Parental occupational class as measure of SES}

Figure F5. Hazard of downgrading by GPA in primary school and parental EGP

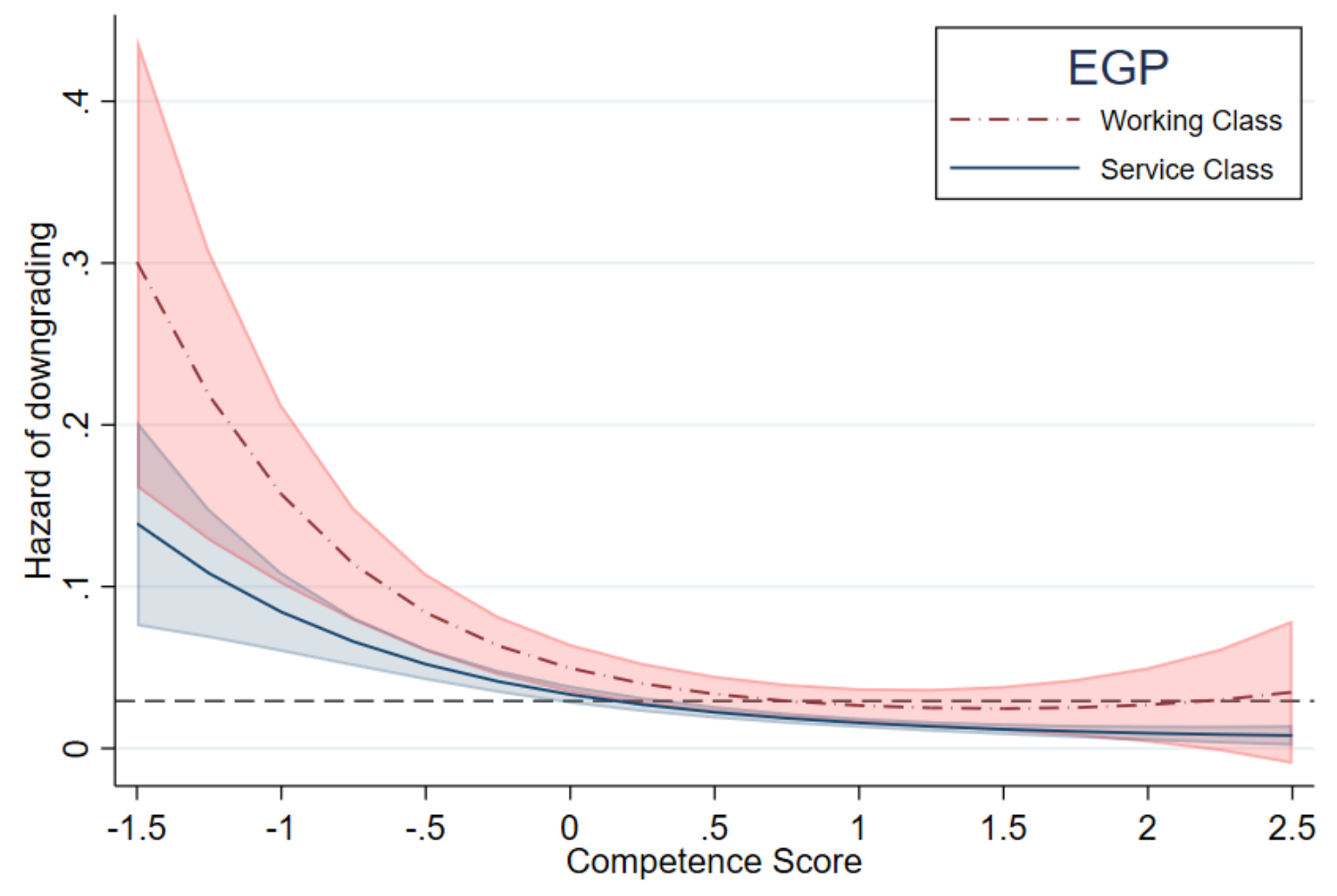


Figure F6. Mediation of the difference in the hazard of downgrading by parental EGP through GPA in Gymnasium

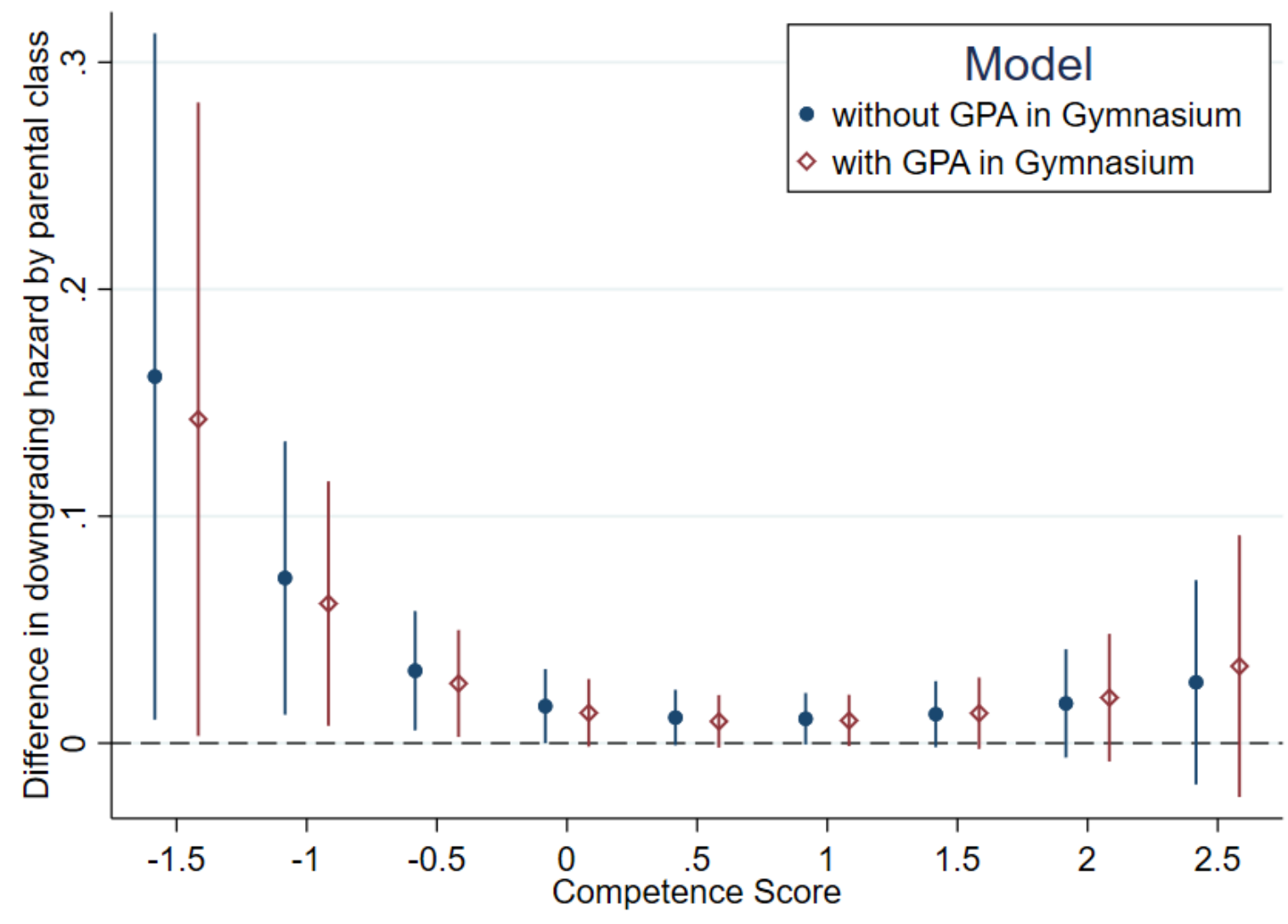


Figure F7. Predicted GPA in Gymnasium by competence score and parental EGP

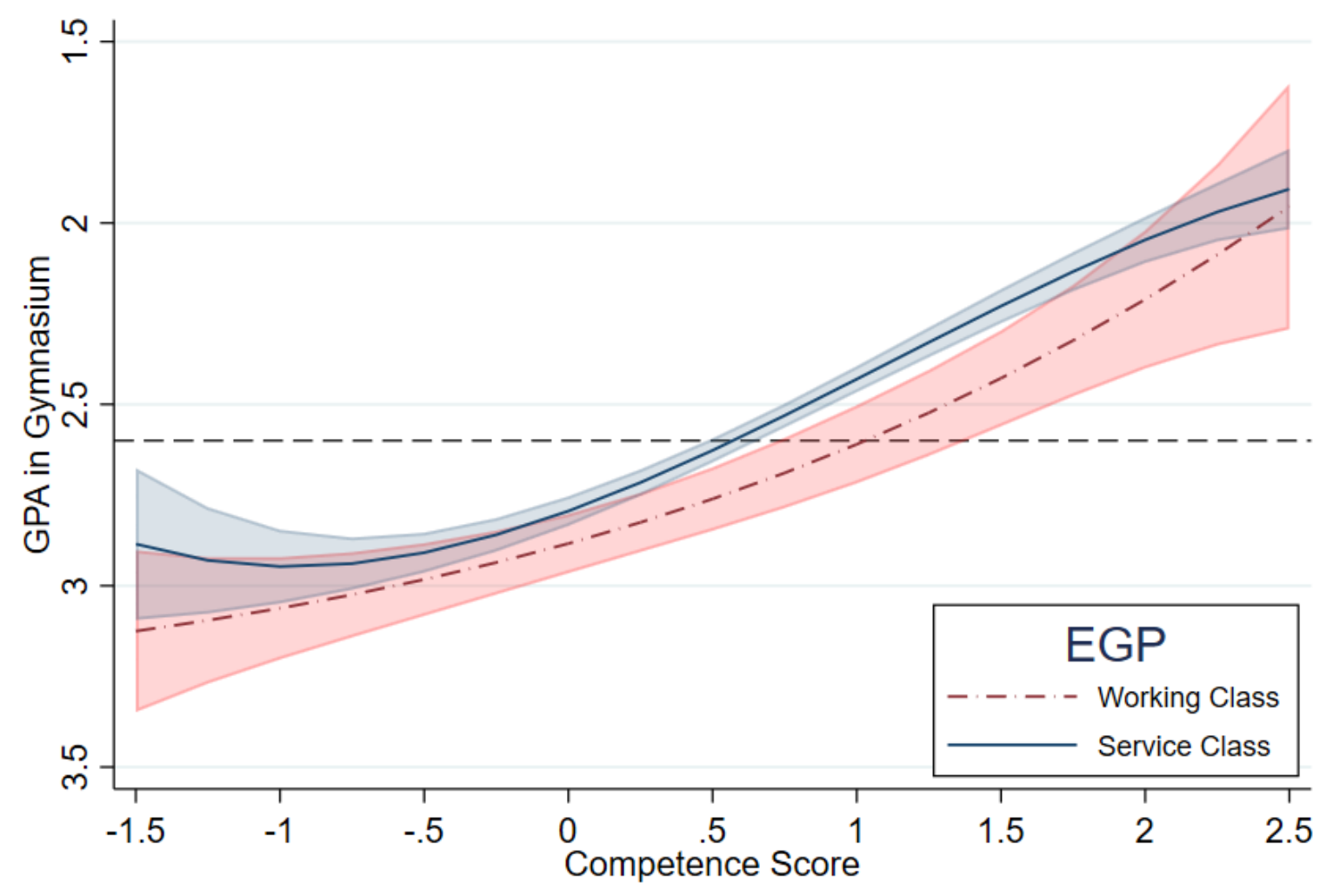


Table F8. Predicted hazard of downgrading by GPA in Gymnasium and parental EGP

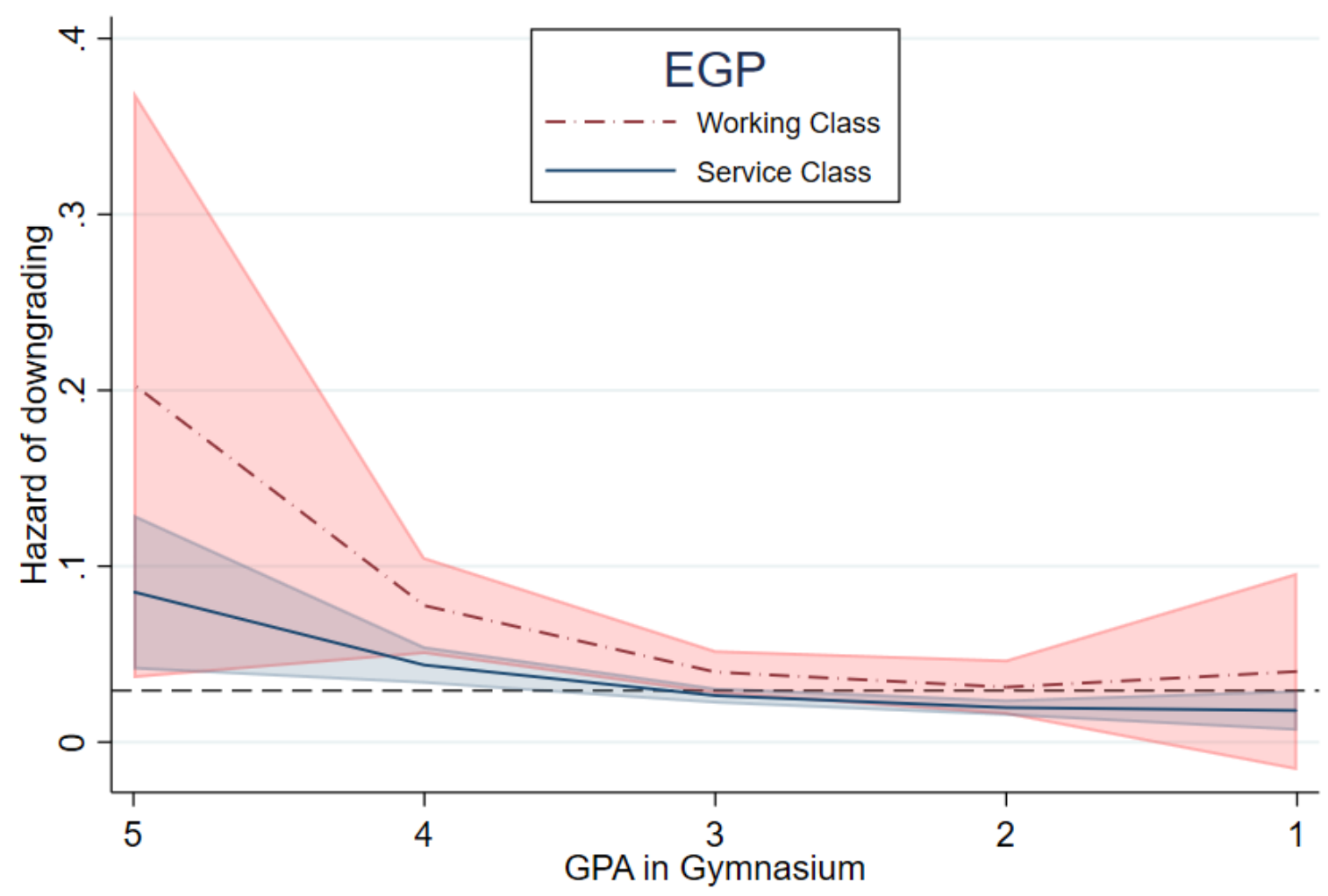

Note: Unlike the analysis with parental education, we treated GPA in Gymnasium as a continuous variable here because for some combinations of GPA in Gymnasium, EGP classes, and survival states, there are too few cases. 


\section{References supplementary materials}

Bayer, M., Goßmann, F., \& Bela, D. (2014). NEPS Technical Report: Generated school type variable t723080_g1 in Starting Cohorts 3 and 4. Bamberg: Leibniz Institute for Educational Trajectories. https://www.neps-data.de/Portals/0/Working\%20Papers/WP_XLVI.pdf

Hernán, M. A. \& Robins, J. M. (2020). Causal Inference: What If. Boca Raton: Chapman \& Hall/CRC. 